
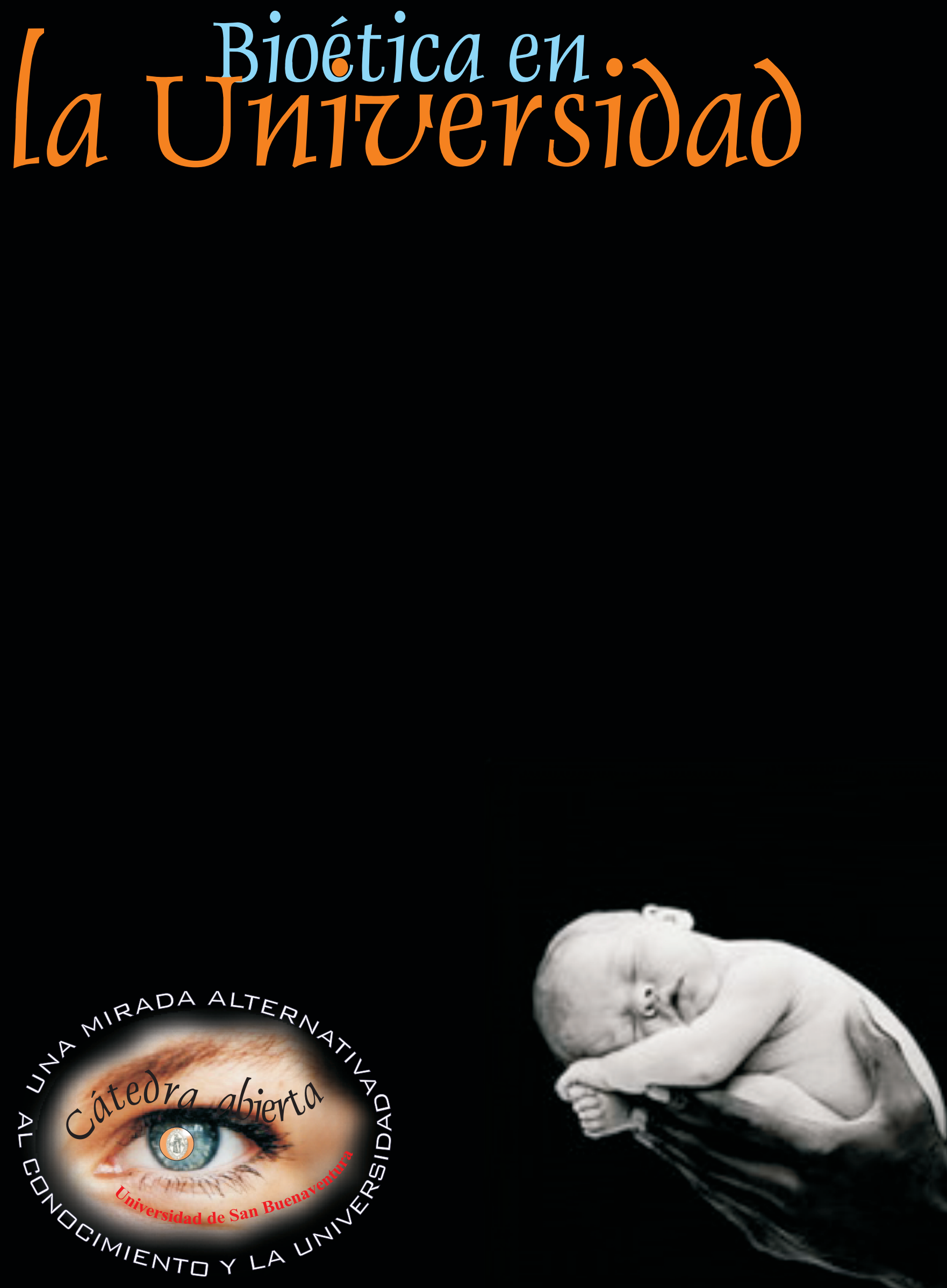


\section{Impacto Ambental y Social del Vertimiento de Residuos Sólidos y Escombros Sobre la Calidad del Río Medellín y Algunos de sus Afluentes}

Enviromental and Social Impact of the Pouring of Solid Waste and Debris About the Quality of the Medellin River and Some of its Affluents.

\section{Resumen:}

La investigación que se desarrolla a continuación, tiene como objetivo principal evaluar la influencia del vertimiento de residuos sólidos domiciliarios y escombros sobre la calidad del río Medellín y algunos de sus afluentes principales como la quebrada La Hueso, La Iguaná y La García, bajo criterios sanitarios, ambientales y sociales. Se utilizó el método teórico práctico, que aborda el problema de la disposición inadecuada de residuos domiciliarios y escombros sobre las laderas y lechos de las quebradas objeto de estudio, estableciendo en la realidad social una explicación veraz y oportuna de la ocurrencia de dichas prácticas de disposición.

El trabajo de campo permitió realizar monitoreos de la calidad de agua a través de los parámetros $\mathrm{DBO}_{5}, \mathrm{DQO}$, sólidos suspendidos, disueltos y sedimentables, $\mathrm{pH}$, oxígeno disuelto, conductividad y turbiedad, así como la cuantificación y determinación de la composición física de algunos de los materiales encontrados sobre las márgenes y laderas más próximas al cauce. De la misma forma, se determinaron composiciones granulométricas de escombros y materiales de arrastre, se analizaron las causas generadoras de la situación problema y se formuló un esquema de gestión que incluyó cada uno de los componentes del manejo integral de los residuos sólidos. Los recorridos de campo y las metodologías de selección cualitativas y cuantitativas, permitieron clasificar las quebradas bajo tres problemáticas preponderantes: La García con vertimientos recurrentes de escombros, La Hueso con presencia de materiales de arrastre como consecuencia de la explotación en canteras y La lguaná con el vertimiento de residuos sólidos domiciliarios.

En términos generales puede deducirse que la transformación del paisaje de cada una de las quebradas es alta, debido a la gran intervención antrópica relacionada con la

'Ingeniera Ambiental Universidad Nacional de Colombia. Magíster en Ingeniería Universidad de Antioquia. Docente Institución Universitaria, elizacarvajal1@gmail.com 
explotación de materiales, vertimientos de aguas residuales, escombros, residuos domiciliarios, ganadería, entre otros. Estas a su vez generan problemas como erosión, pérdida de las coberturas vegetales, malos olores, proliferación de vectores, entre otros, además de los graves problemas hidráulicos que desencadenan socavación de márgenes, desbordamientos e inundaciones, que afectan las comunidades cercanas a la microcuenca. Finalmente, el análisis de causalidad determinó que el origen de la problemática estudiada no solo recae en el generador, sino por el contrario se constituye en una responsabilidad compartida de autoridades ambientales, empresas de aseo, autoridades de control, entre otros. El esquema de gestión propuesto tiene como pilar fundamental "La educación y prevención", entrelazado con un marco normativo y elementos sociales y técnicos, componentes indispensables para garantizar que toda la gestión de los residuos funcione satisfactoriamente en la región.

\section{Palabras Claves:}

Residuos sólidos domiciliarios, escombros, materiales de arrastre, microcuencas, gestión integral de residuos sólidos, disposición inadecuada.

\section{Abstract:}

This research aims at evaluating the influence of the pouring of home solid waste and debris about the quality of the Medellin River and some of its main tributaries such as the La Hueso, La lguaná and La García streams, under sanitary, environmental, and social criteria. A theoretical-practical method was used, which deals the issue of the inadequate disposal of home waste and debris on the hillsides and beds of streams being the object of the study, establishing in the social reality a truthful and timely explanation of the occurrence of those practices of disposal.

The field work contributed to carry out the monitoring of the quality of water through the application of parameters like $\mathrm{DBO}_{5}, \mathrm{DQO}$, suspended, dissolved and sedimentary solids, $\mathrm{pH}$, dissolved oxygen, conductivity and cloudiness, as well as the quantity and the determination of the physical make-up of some of the materials found on the banks and the hillsides which are next to the riverbed. Likewise, the granulometric make-up of debris and dragging materials was determined, the causes leading to the situation were analyzed and a management scheme was drawn up and it included each and every one of the components of the integral management of solid waste. The field trips and the qualitative and quantitative research methods, allowed the classification of streams under three key issues: The La García Stream with recurring pouring of debris; the La Hueso Stream with dragging materials as a consequence of the exploitation of quarry and the La Iguaná Stream with the pouring of home solid waste. In general terms, it can be deduced that the transformation of the landscape of every stream is high, due to the anthropic intervention related to the exploitation of materials, pouring of waste water, debris, home waste, livestock and the like. All of these factors, in turn, generate problems such as 
erosion, loss of the layers of vegetation, smelly odors, proliferation of vectors, among others, as well as the serious hydraulic problems which cause undermining of banks, overflowing and floods, which affect those communities near the small basins.

Lastly, the analysis of causality determined that the origin of the issue studied not only falls on the source, but it becomes a shared responsibility of environmental authorities, cleaning enterprises, control authorities, etc. The management scheme proposed has as its fundamental pillar "Education and Prevention," interwined with a regulatory framework and social and technical elements, are necessary components in order to guarantee that the whole management of waste materials works satisfactorily in the region.

\section{Key words:}

Home solid waste, debris, dragging material, small basins, integral management of solid

\section{Introducción}

La gestión integral de los residuos sólidos, ha sido un tema de gran trascendencia en las dos últimas décadas a nivel internacional, nacional, regional y local debido a los altos niveles de criticidad y complejidad que el manejo de los mismos conlleva. En países en vía de desarrollo como lo son los de América Latina, son pocos los recursos económicos para la investigación y desarrollo de nuevas tecnologías para el tratamiento y disposición final de los residuos, se observa gran precariedad en la aplicación de leyes y normas pese a que se cuentan con ellas, y se presenta poco sentido de pertenencia y cultura de la comunidad para lograr un buen manejo de éstos.

Desde un contexto nacional, nuestro país no es ajeno al tema a pesar que diferentes organismos privados y públicos, como el Gobierno Nacional y Regional, las Administraciones Municipales, sector educativo, entre otros, los cuales han realizado esfuerzos a nivel económico y científico para superar los conflictos ambientales y sociales en particular pero no exclusivo, sobre el manejo de los residuos sólidos domiciliarios y escombros, en lo que se refiere al componente de disposición final.

Es de resaltar que los vertimientos a fuentes de aguas, se presenta con mayor frecuencia y como solución inmediata en la mayoría de las ciudades del país; debido a que muchas zonas especialmente en las áreas periféricas de difícil acceso y en áreas rurales, no se cuenta con un servicio de recolección oportuna de los residuos, que coincide con un bajo nivel económico y cultural, por lo cual se ven avocados a realizar este tipo de prácticas de disposición, que aunque no sean las más adecuadas, les permite evacuar los residuos que se generan en cada 
una de las instalaciones domiciliarias. Es el caso de algunos de los municipios que conforman el Área Metropolitana del Valle de Aburrá, ya que a pesar que las empresas de aseo que operan en esta región reportan coberturas de recolección que superan el $95 \%$, gran cantidad de residuos sólidos, no son llevados a los rellenos sanitarios oficialmente establecidos y autorizados, sino que se disponen en las fuentes de agua superficiales o en el peor de los casos en el río Medellín, generando impactos ambientales de gran relevancia. El vertimiento de residuos sólidos domiciliarios y escombros genera graves conflictos a nivel físico-químico, sanitario y paisajístico de las microcuencas y del río Medellín, se convierte en una fuente de alto riesgo para las comunidades asentadas en los alrededores y para la población en general, no solo por la disminución en la calidad del recurso agua que la contaminación de éste evento genera, sino por la posible ocurrencia de catástrofes relacionadas con la obstrucción y disminución de la capacidad hidráulica de los cauces y consecuente deslizamiento y movimiento en masa de tierra y escombros represados. Igualmente, se incurre en el detrimento de la calidad de vida de la población debido a la proliferación de vectores, al aumento de la morbilidad infantil y adulta plasmada en infecciones respiratorias agudas, enfermedades digestivas agudas, paludismo, parasitismo, entre otras. Por consiguiente y debido a la grave problemática que se genera sobre el recurso agua, sobre el bienestar social y la calidad de vida de la población, el proyecto de investigación tiene la finalidad de evaluar el impacto que se genera por prácticas inadecuadas de disposición final de residuos sólidos domiciliarios y escombros en algunas de las microcuencas de los municipios que conforman el Área Metropolitana del Valle de Aburra, relacionado con la ocupación de cauces, disminución en la calidad de los cuerpos agua y afectaciones paisajísticas que dicho evento ocasiona.

\section{Metodología}

Para abordar la investigación, se construyo una metodología apoyada en métodos y técnicas, dada la necesidad de explorar campos nuevos, o bien, poco conocidos sobre la temática de investigación. El método seleccionado fue el teórico-práctico. La operacionalización del método desde lo teórico, permitió un desarrollo sobre el objeto de estudio, o sea, la revisión detallada de la información reportada a través de la literatura sobre el tema de estudio y desde lo práctico consistió en la selección de técnicas que se relacionaron con el medio y que se usaron para recolectar, procesar y analizar la información sobre el objeto de estudio en el contexto regional.

El método permitió tener un acercamiento real al problema de estudio, estableciendo en la realidad social una explicación veraz y oportuna de los conflictos ambientales desencadenados por las inadecuadas prácticas de disposición final de residuos sólidos y escombros en nuestra región. Se diagnosticaron y analizaron las zonas y/o microcuencas de la región que presentan las problemáticas ambientales ya mencionadas, se diseñaron y aplicaron encuestas y entrevistas a las comunidades afectadas; se evaluaron en el sitio las características del entorno, del paisaje, 


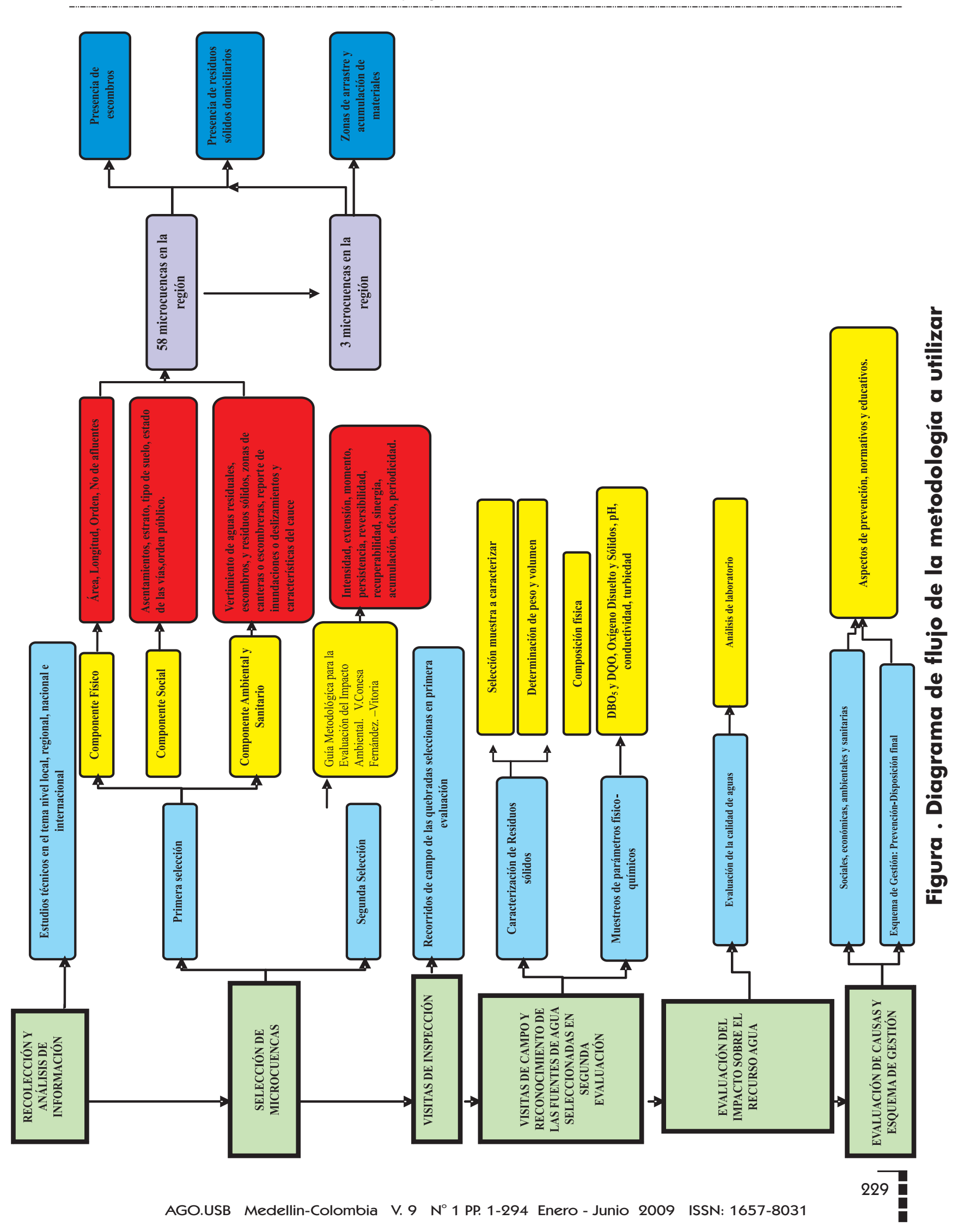


del recurso agua y su grado de afectación, así como el análisis de las posibles causas que conllevan a que dichas prácticas se presenten, y se formula un esquema de gestión que posibilite la solución de la problemática. Seguidamente y con relación a la selección de las técnicas, se tuvo en cuenta que no existen reglas ya establecidas para realizar el análisis de la información y desarrollo de la investigación. Las tradiciones investigativas, han generado una serie de procedimientos analíticos, de uso común entre los investigadores, razón por la cual se seleccionaron las siguientes técnicas: análisis de contenido, la observación, la entrevista, la encuesta y la experimentación.

\section{Resultados y análisis}

\subsection{Primera selección de las cuencas que presentan mayor afectación en la región}

Como primera medida se hizo un recopilación de información, en la cual se establece que el río Medellín a lo largo de su recorrido de sur a norte cuenta con mas de 200 corrientes, unas con mayor importancia que otras, por lo cual se construyó un procedimiento que condujera a la selección de aquellas que requirieren un estudio más detallado y presenten afectaciones biológicas, sanitarias, hidráulicas y paisajísticas considerables. Se descartaron aproximadamente 100 afluentes por su tamaño, caudal intermitente, orden y poca significancia en la región de estudio. Por lo anterior, se planteó la construcción de una primera matriz que permita listar y valorar posteriormente las microcuencas que conforman la región que presentan mayores dificultades de manejo y conflictos relacionados con los residuos sólidos.

En la selección de las microcuencas objeto de monitoreo se tomaron como referencia criterios ambientales, sanitarios, sociales y económicos. Las microcuencas se distribuyen a lo largo del Valle de Aburrá, no solo en municipios o en zonas donde se concentre población de bajos recursos o población que carezca del servicio de aseo, sino también en aquellas áreas donde se radican los estratos superiores y que cuentan con buenas calidades de vida. Posteriormente se seleccionaron 58 microcuencas que por su importancia en la región, tamaño, características físicas, problemáticas ambientales y sanitarias asociadas a la presencia de residuos sólidos y escombros, disponibilidad de información y el conocimiento empírico que se tiene de ellas, requieren ser objeto de estudio en la presente investigación; ésta primera evaluación, arrojó un grupo de 11 microcuencas las cuales se agruparon en 3 grandes categorías, así: quebradas con presencia de escombros por estar asentadas en zonas de influencia de canteras, escombreras o zonas de extracción de materiales, quebradas con presencia de residuos sólidos por bajas coberturas de recolección, niveles inferiores de los estratos socioeconómicos o bajos 
niveles educativos y culturales, y quebradas donde se presenta el arrastre o confluencia de residuos o escombros. Las quebradas seleccionadas en la primera evaluación son:

\section{Tabla 1 . Quebradas seleccionadas en primera evaluación}

\begin{tabular}{|c|c|c|c|}
\hline Municipio & Nombre Quebrada & Municipio & Nombre Quebrada \\
\hline Medellín & Jabalcona & Medellín & Santa Elena \\
\hline Medellín & Altavista & Medellín & El Molino \\
\hline Medellín & La Picacha & Itagüí & Doña María \\
\hline Medellín & La hueso & Bello & La García \\
\hline Medellín & La Iguaná & Medellín & La Rosa \\
\hline & \multicolumn{3}{|c}{} \\
\hline
\end{tabular}

\subsection{Visitas De Inspección Inicial A Las Zona De Interés}

Con la aplicación de la matriz de evaluación mostrada en el ítem anterior, se realizaron las visitas las microcuencas que presentan mayor criticidad. Las visitas de inspección inicial permitieron verificar y constatar que los puntos o microcuencas que reporta la literatura son focos permanentes de contaminación ambiental, o por el contrario, la situación se presenta de forma temporal por dificultades en la recolección de residuos por parte de la empresa de aseo. En cada visita se diligenció el formulario de recolección de microcuencas para facilidad en la captura de información. Se aplicaron aproximadamente 60 encuestas y 50 entrevistas a la población asentada de las zonas donde se presenta la problemática en cuestión, para conocer la percepción de la comunidad frente al tema y tener un contexto inicial de las áreas a estudiar.

\subsection{Segunda Selección De Microcuencas}

Dado al alto número de las microcuencas preseleccionas, contra los alcances y costos del proyecto, se optó por construir un segundo tamiz de selección de las microcuencas evaluadas y escogidas a partir de la primera matriz, se utilizó la metodología de Vicente Conesa Fernandez (1997), aplicable a la evaluación del impacto ambiental en proyectos en los cuales se presenta intervención directa de los recursos naturales y el medio ambiente. Aunque dicha metodología se utiliza tradicionalmente en evaluaciones de impacto ambiental por el desarrollo de proyectos de gran envergadura, se consideró su utilización dentro de la investigación ya que califica de manera integral el impacto ambiental que puede generar cierta actividad antrópica, a pesar de que ésta no se enmarque dentro de proyecto específico. 
La calificación que se obtiene con la metodología de Vicente Conesa permitió hacer un tamiz mas fino de las quebradas, obteniendo como resultado tres quebradas relevantes en la región como son La Hueso, La Iguaná y la García, cuyo trabajo de campo corroboró la problemática estudiada. La metodología Conesa evalúa criterios como: Naturaleza (+o-), extensión (área de influencia), persistencia (permanencia del efecto), sinergia (regularidad de la manifestación), efecto (relación causa-efecto), recuperabilidad (reconstrucción por medios humanos), intensidad (grado de destrucción), momento (plazo de manifestación), reversibilidad, acumulación (incremento progresivo), periodicidad (regularidad de la manifestación).

Las microcuencas seleccionadas para evaluar la influencia del vertimiento de residuos sólidos y escombros, realizarles monitoreo y mediciones de calidad de aguas y residuos vertidos son:

- Quebrada La Iguaná: dado que su calificación es 51 puntos, según este valor, los impactos por el vertimiento de residuos sólidos pueden considerarse como SEVEROS. Es importante aclarar que la quebrada La Iguaná, desde su nacimiento hasta su desembocadura, presenta los tres criterios de selección, siendo la más importante la presencia de residuos sólidos domiciliarios en las laderas y directamente en su cauce. Barrios como La lguaná, El Volador, El Pesebre y Robledo Las Margaritas, evidencian dicha problemática, debido principalmente bajos niveles socioeconómicos y educativos, al poco sentido de pertenencia, y a las dificultades en el servicio de recolección por parte de la empresa de aseo.

- Quebrada la García: con calificación obtenida de 63 puntos. De acuerdo con este valor, los impactos por el vertimiento de escombros pueden considerarse como SEVEROS. Muchos de los barrios de influencia de la quebrada la García, utilizan sus márgenes como botaderos clandestinos de escombros, ocasionando graves problemas de erosión de laderas, cambios en el paisaje y aportes de sedimentos que disminuyen la calidad del agua. Sumado a esto, en la parte alta se presentan algunas canteras, que contribuyen de manera considerable a agravar el problema.

- Quebrada La Hueso: obtuvo 53 puntos. De acuerdo con este valor, los impactos por estar en zona de influencia de ladrilleras, canteras y/o escombreras pueden considerarse como SEVEROS. La quebrada la hueso a lo largo de todo su recorrido evidencia gran cantidad de sedimentos, y prueba de ello es la extracción de arenas y canto rodado en los barrios Eduardo Santos, Antonio Nariño, San Javier y Naranjal. También se observan residuos y escombros en márgenes y cauces en la parte alta de la microcuenca.

Como común denominador, se observa que las tres microcuencas presentan arrastre de residuos sólidos a lo largo de todo el cauce, provenientes de la parte alta, y que son transportados por la corriente hasta zonas mas bajas. Algunos de ellos se quedan retenidos en las laderas sufriendo un proceso paulatino de descomposición, mientras que los menos densos flotan sobre la 
superficie, como el caso de los plásticos. De otro lado, los escombros vertidos a las riberas también sufren el mismo efecto del arrastre hasta zonas mas bajas, especialmente aquellos que por su peso específico pueden ser arrastrados por la corriente, como en el caso de maderas, tejas y materiales bituminos. Los materiales mas pesados generalmente se acumulan en las laderas aumentando los valores de parámetros como los sólidos suspendidos y turbiedad. Finalmente, parte de los escombros y residuos sólidos arrastrados por la corriente no solo provienen de los barrios de influencia de las quebradas objeto de estudio, sino también de sus quebradas afluentes que recorren zonas diferentes, pero con población en situaciones socioeconómicas similares a las estudiadas en la investigación.

\subsection{Evaluación de calidad de aguas}

Los parámetros analizados en el laboratorio para las quebradas La García, La lguaná y La Hueso. fueron $\mathrm{DBO}_{5}, \mathrm{DQO}$ sólidos suspendidos, sólidos disueltos, sólidos sedimentables, conductividad, turbiedad, $\mathrm{pH}$ y oxígeno disuelto. Estos análisis de laboratorio se realizaron según técnicas establecidas en el Standar Methods for the examination of water and waste water. De igual manera se describen las estaciones y fechas de realización de los muestreos.

Tabla . Estaciones para el muestreo de la calidad del agua, quebradas La García, La Iguaná y la Hueso

\begin{tabular}{|c|c|c|c|c|c|}
\hline Quebrada & $\begin{array}{c}\text { Fecha de } \\
\text { Muestreo } \\
2008 \\
\end{array}$ & $\begin{array}{l}\text { Estación } 1 \\
\text { Parte Alta }\end{array}$ & $\begin{array}{c}\text { Estación } 2 \\
\text { Parte Media }\end{array}$ & $\begin{array}{l}\text { Estación } 3 \\
\text { Parte Baja }\end{array}$ & $\begin{array}{l}\text { Estación } 4 \\
\text { Parte Baja }\end{array}$ \\
\hline La García & 13 de junio & Tierra Adentro & $\begin{array}{l}\text { Barrio El Congolo. } \\
\text { (Carrera } 54 \text { con calle } \\
63 \text { ). }\end{array}$ & $\begin{array}{l}\text { Barrio Prado. } \\
\text { (Calle } 50 \text { con } \\
\text { avenida 43.) }\end{array}$ & $\begin{array}{l}\text { Estación de Policía } \\
\text { de Bello. (Avenida } \\
43 \text { con calle 50). }\end{array}$ \\
\hline La Iguana & 19 de julio & $\begin{array}{l}\text { Corregimiento de San } \\
\text { Cristóbal, (Carrera } 144 \\
\text { con calle } 63 \text { sobre la } \\
\text { ladrillera San } \\
\text { Cristóbal.) }\end{array}$ & $\begin{array}{l}\text { Carrera } 73 \text { con calle } \\
58^{a} \text {, sobre el centro } \\
\text { de acopio de } \\
\text { Escombros de } \\
\text { Empresas Varias de } \\
\text { Medellín }\end{array}$ & $\begin{array}{l}\text { Carlos E. } \\
\text { Restrepo, } \\
\text { (Carrera 63 } \\
\text { con Calle 58). }\end{array}$ & \\
\hline La Hueso & $\begin{array}{l}07 \text { de } \\
\text { agosto }\end{array}$ & $\begin{array}{l}\text { Urb. Quintas de San } \\
\text { Michael. (Calle 43B con } \\
\text { carrera 115) }\end{array}$ & $\begin{array}{c}\text { Barrio Santa Lucia } \\
\text { (Carrera } 85 \text { con calle } \\
47 D)\end{array}$ & $\begin{array}{l}\text { Carrefour de } \\
\text { la } 65 . \\
\text { (Carrera } 65 \\
\left.\text { con calle } 48^{\mathrm{a}}\right) .\end{array}$ & \\
\hline
\end{tabular}

En la quebrada La García se monitorearon 4 estaciones debido a que cuenta con mayor número de puntos críticos de la problemática objeto de estudio. 


\subsubsection{Cargas y análisis de calidad de aguas en las quebradas de estudio}

Se calculó la carga en términos de: Demanda Bioquímica de Oxibeno $\left(\mathrm{DBO}_{5}\right)$, Demanda Química de Oxígeno (DQO), Sólidos Suspendidos (SS) y Sólidos Disueltos (SD), para determinar la cantidad de sustancias orgánicas e inorgánicas aportadas a las microcuencas producto de fuentes de contaminación, entre ellas, el vertimiento de residuos sólidos y escombros, como la explotación minera que se da en éstas. También se midieron valores como Turbiedad, oxígeno disuelto, conductividad y sólidos sedimentables.

\subsubsection{Cargas quebrada La Iguaná}

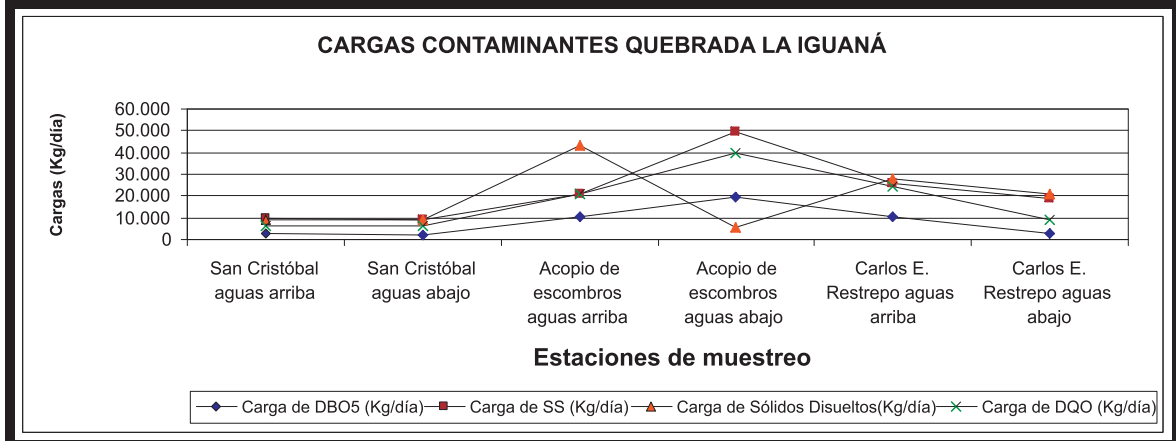

Gráfico 1 . Distribución de la cargas en la quebrada la Iguaná

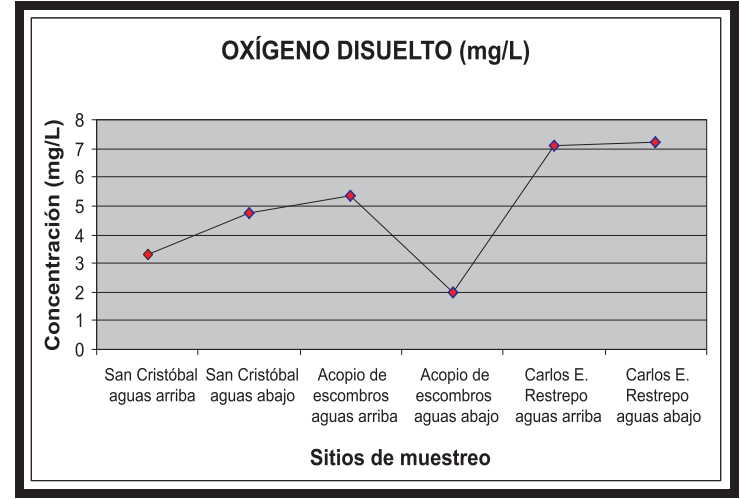

Gráfico2. Comportamiento del Oxígeno Disuelto, quebrada la Iguaná

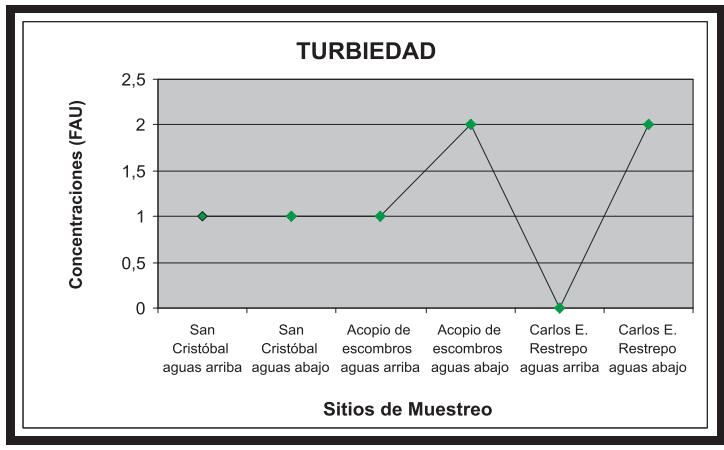

Gráfico 4 . Turbiedad, quebrada La Iguaná

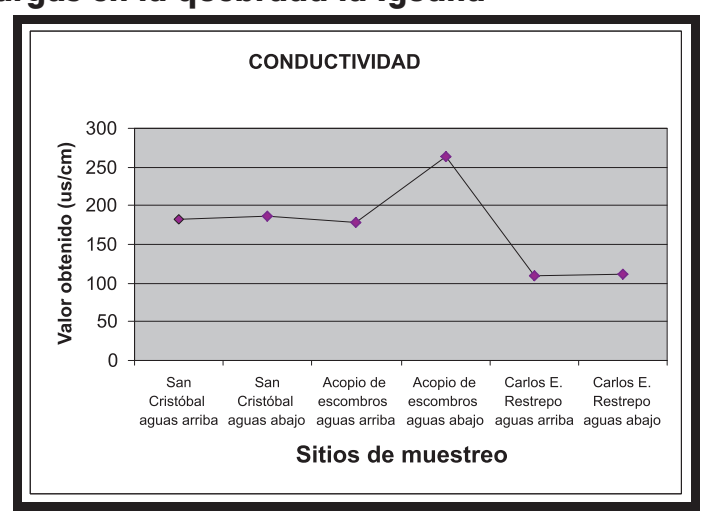

Gráfico 3 . Conductividad, quebrada la Iguaná

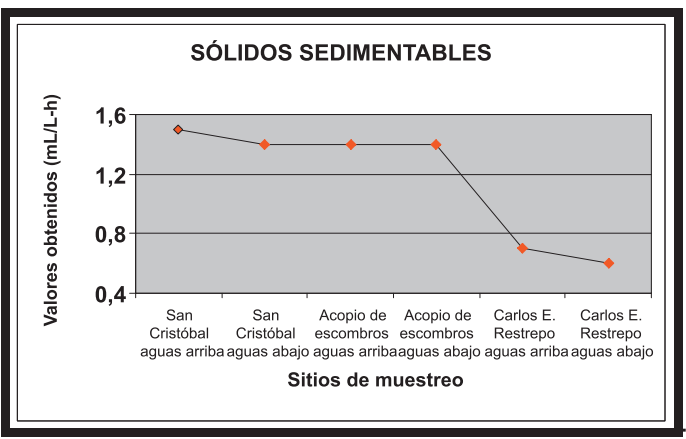

Gráfico 5 . Sólidos Sedimentables, quebrada La Iguaná 
Los valores de la carga para $\mathrm{DBO}_{5}$, SS y $\mathrm{DQO}$ presentan comportamientos muy similares a lo largo de la quebrada La lguaná y presentan valores característicos de aguas contaminadas con aportes de materia orgánica, siendo la estación Acopio de Escombros aguas arriba y abajo la más crítica por sus altos valores.

Pese a que solo se realizó un muestreo puntual, puede establecerse que si se presentan afectaciones en la quebrada por el vertimiento de residuos sólidos y escombros, comprobándose la hipótesis de la investigación, hecho que la convierte en una microcuenca crítica para la ciudad y región; dicha microcuenca quedó seleccionada dentro de la segunda evaluación, como una quebrada cuya problemática preponderante es el vertimiento de residuos sólidos domiciliarios. Los recorridos de campo permitieron evidenciar que no sólo éste criterio es el causante de los parámetros de calidad de agua ya analizados, sino que presentan una combinación de las tres problemáticas, que son en su orden vertimiento de residuos, de escombros y extracción de materiales. Desde su parte alta hasta la desembocadura hay presencia de dichos materiales, además de los remanentes de actividades extractivas. Estos repercuten en aumentos de materia orgánica, que se ven reflejados en los parámetros de $\mathrm{DBO}_{5}$, DQO y sólidos disueltos, así como de los valores de sólidos suspendidos que aportan mayor turbiedad y color al recurso.

La revisión bibliográfica, permitió establecer que sólo se ha diagnosticado la problemática en diferentes documentos técnicos, pero no se tienen estudios en los cuales se modele el arrastre de materiales o residuos objeto de estudio a lo largo de la microcuenca, ni la estimación de las cantidades vertidas sobre el cauce y laderas. Sólo se tienen algunos estudios técnicos sobre diseños de estructuras hidráulicas, aforos y mediciones de caudal y velocidad, estimación de tiempos de retorno de lluvias, capacidad de canales, entre otros, previendo posibles inundaciones y desbordamientos. Desde el punto de vista económico, se han invertido sumas considerables de dinero para solucionar hidráulicamente algunas de las problemáticas de la quebrada como son la construcción de disipadores de energía, gaviones, muros de contención y canales en concreto en algunos tramos; también se ha dispuesto de cuadrillas adicionales por parte de la Empresa de Aseo y del Municipio para la limpieza de lechos y cauces, que eviten taponamientos y tragedias mayores, lo cual acarrea sobrecostos en la operación del servicio de aseo.

Las situaciones ya expuestas sobre La lguaná, repercuten directamente sobre la calidad del Río Medellín en vista que la descarga se presentan de manera puntual y continua. Los residuos flotantes, materia orgánica en proceso de descomposición, arenas finas y gruesas, canto rodado, entre otros, son arrastrados por la corriente desde sus lugares de origen hasta la desembocadura en el río, que por las mismas condiciones de transporte se depositan en las zonas de embalse generando problemas en la operación del Complejo Hidroeléctricos de Porce, así como deterioros de las estructuras hidráulicas, vías y equipamientos urbanos, aguas 
abajo de la cuenca. Pese a que el río va degradando la materia orgánica y se va autorecuperando gradualmente a medida que continúa con su recorrido, es tanto el aporte que sufre de diversas fuentes receptoras, que su proceso de descontaminación no puede darse por si mismo, sino que requiere de soluciones técnicas que minimicen, mitiguen y corrijan los impactos ambientales y sanitarios producto de las actividades antrópicas.

\subsubsection{Cargas quebrada La García}

Vale la pena resaltar que La García es una quebrada completamente intervenida por la acción antrópica; se presenta invasión de retiros, vertimientos permanentes de aguas residuales, residuos sólidos domiciliarios y escombros. En la segunda evaluación de selección, permitió establecer que la problemática preponderante a lo largo de la cuenca es el vertimiento de escombros, razón por la cual se analizan los efectos que éstos ocasionan sobre la calidad del recurso.

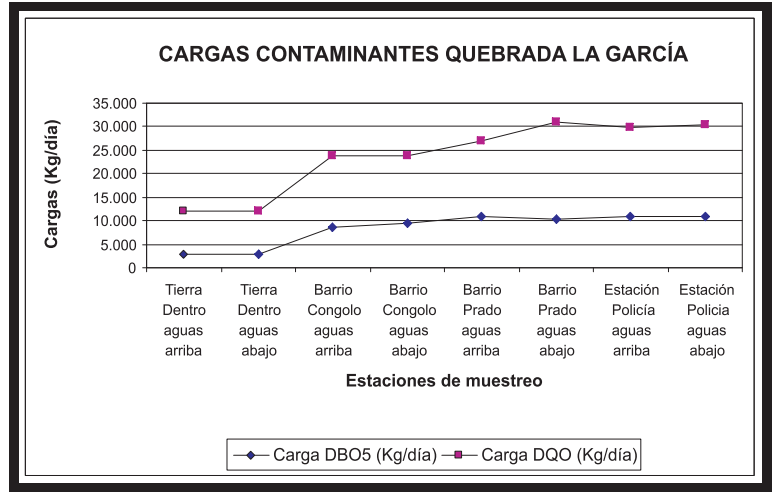

Gráfico 6 . Distribución de las carga de DBO5 en Kg/día, quebrada La García

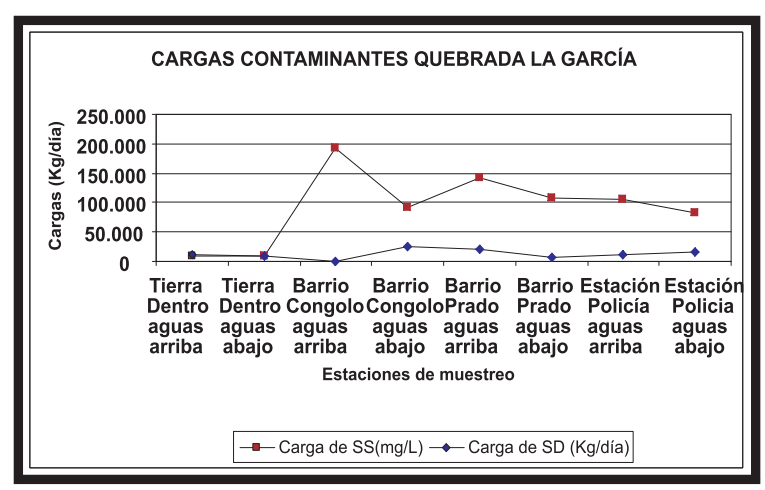

Gráfico 7 . Distribución de las cargas de sólidos suspendidos en $\mathrm{Kg} /$ día, quebrada La García

A pesar que los residuos sólidos domiciliarios dispuestos en las laderas y cauces, como los arrastrados por la corriente, aportan cargas orgánicas al agua, no es ésta situación la que aumenta en mayor proporción los valores de las cargas de $\mathrm{DBO}_{5}$ y $\mathrm{DQO}$ en cada una de las estaciones de monitoreo. Son las descargas de aguas residuales sin ningún tipo de tratamiento, directamente desde las viviendas o desde las redes de alcantarillado, las que ocasionan un incremento considerable en los valores de los parámetros mencionados. Sólo en la estación Prado, aguas abajo, se evidenció la presencia de residuos sobre laderas y cauce, que en su mayoría son de naturaleza orgánica, los cuales pueden estar influyendo en aumento de cargas orgánicas mencionadas, en las demás estaciones, sólo se observaron residuos flotantes arrastrados por la corriente. La parte alta de la quebrada, se ha caracterizado por ser una zona de explotación de materiales de tipo legal e ilegal, extrayendo arenas, canto rodado y rocas de diversos tamaños. Esta actividad ha contribuido en un alto porcentaje a incrementar los sólidos, 
entre ellos los suspendidos y sedimentables, que le aportan un aspecto físico desagradable y alta turbiedad al agua.

Puede afirmarse que los sólidos, especialmente los suspendidos, son los que influyen en mayor proporción al deterioro de la calidad del agua por la alta turbiedad y color que se presenta a lo largo de la microcuenca. Desde la zona rural en la cual se desarrollan actividades extractivas a través de canteras, sumado a la erosión del suelo generada por el sobrepastoreo del ganado de la zona, se aportan cantidades considerables de partículas que le dan un aspecto turbio al agua; en la parte media y baja, considerada zona urbana, las prácticas de disposición de escombros sobre laderas y directamente en el cauce, son la causantes de los altos valores de sólidos. El aumento de los sólidos se ve favorecido por las altas pendientes y velocidades que alcanza la quebrada, provocando un efecto de turbulencia. En las épocas de verano, cuando el caudal baja, los fenómenos de sedimentación se incrementan, quedando sólidos y material de playa retenidos sobre el lecho y laderas. Aguas abajo, cerca de la desembocadura del río Medellín, se observa un depósito de materiales de arrastre en ambos costados de la microcuenca, debido a que se presenta un estrechamiento y configuración diferente del canal, pasando de natural a canalizado. Esta situación favorece el aumento de sólidos en el punto de monitoreo estación de Policía aguas abajo. Dichas situaciones limitan las condiciones fisicoquímicas del río Medellín. Debido a la sinuosidad que éste tiene aguas abajo, se genera sedimentación del material suspendido, transportado a través de la corriente. En épocas de verano, dicho proceso se aumenta por el flujo poco turbulento, mientras que en las épocas de lluvias se presentan situaciones contrarias, ya que el caudal es tan alto, que es capaz de de transportar material pesado hasta las zonas de embalse. Además de lo anterior, en los periodos de lluvias se pueden generar procesos erosivos en el cauce y resuspensión de material a causa de los las altas velocidades y turbulencia que se derivan del incremento del caudal.

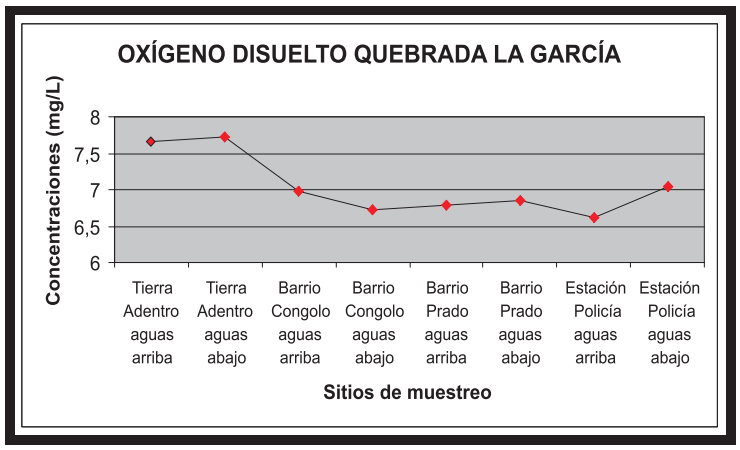

Gráfico 8. Oxígeno Disuelto Quebrada La García

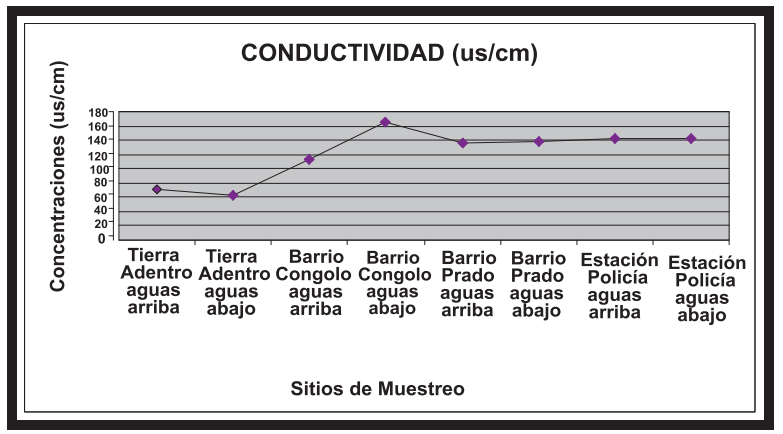

Gráfico 9. Conductividad, Quebrada La García 


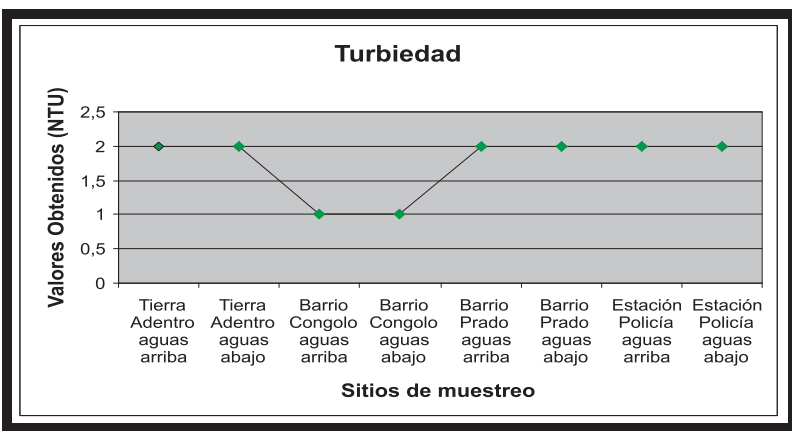

Gráfico 10 . Turbiedad, Quebrada La García

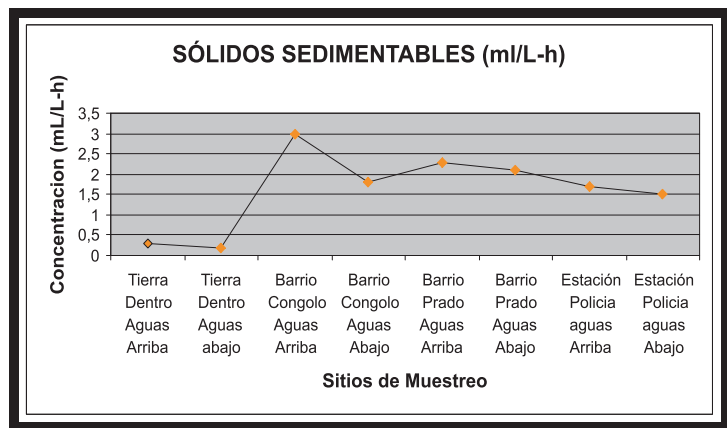

Gráfico 11. Sólidos Sedimentables Quebrada La García

En función de los gráficos anteriores, la problemática preponderante escogida inicialmente para la quebrada La García, si es el vertimiento de escombros, por lo tanto, la influencia de dicha práctica de disposición final es un factor determinante cuando se habla de afectaciones en la calidad del recurso. Además de ésta, otros factores que cobran importancia son la explotación de arenas y otros materiales en la zona alta, así como las características hidráulicas de la microcuenca que favorecen el desplazamiento de rocas y sedimentos a las zonas bajas, poniendo en riesgo a la población ribereña, que por lo general es de bajos recursos. En los últimos meses, la temporada invernal ha incrementado más el problema, ocasionando graves inundaciones el los barrios Zona Industrial No 2, Las Granjas y Prado que generaron pérdidas materiales y reubicación de familias. La Administración Municipal no es ajena a la situación sanitaria, ambiental y social de la microcuenca, ha invertido altos costos en la reubicación de viviendas, acompañamiento social y recuperación de zonas críticas como la cercana a la Estación de Policía del Municipio de Bello, en la cual se están construyendo muros de contención y readecuación de las vías acceso.

Con respecto a los residuos domiciliarios, no se puede desconocer que estos afectan la calidad del recurso, sin embargo, no es la problemática más importante; por tal motivo la hipótesis de la investigación sobre los residuos domiciliarios no se comprueba totalmente. Es el vertimiento de aguas residuales domésticas las que aportan en mayor porcentaje carga orgánica; las descargas de aguas se observan a lo largo de toda la cuenca, provenientes de las viviendas que se encuentran sobre las laderas y de las redes de alcantarillado del municipio. La premisa acerca del efecto de los escombros y materiales de arrastre presenta mayor confiabilidad, ya que los valores de cargas de sólidos suspendidos y la turbiedad demuestran los deterioros sobre la calidad del agua. Las afectaciones del río Medellín por la descarga de la quebrada La García saltan a la vista, especialmente del punto de vista hidráulico. Aunque gran parte del material de arrastre se queda represado antes del canal de desembocadura, el caudal de la quebrada hace que se descarguen algunos de éstos al río, y más aún en la época de invierno. El arrastre de los materiales genera socavación sobre las márgenes y pérdida de las placas de concreto del canal. 
Durante el mes de agosto, la fuerte temporada invernal afectó el canal de entrega de La García al río Medellín, produciendo la caída de árboles y deterioro del canal.

\subsubsection{Cargas quebrada La Hueso}

De acuerdo con los recorridos de campo, la problemática recurrente a lo largo de Quebrada La Hueso es la presencia de materiales de arrastre producto de la explotación a través de canteras, que incide especialmente en el aporte de sólidos en suspensión y en la turbiedad del recurso. En menor escala se encuentran los vertimientos de residuos sólidos y escombros.

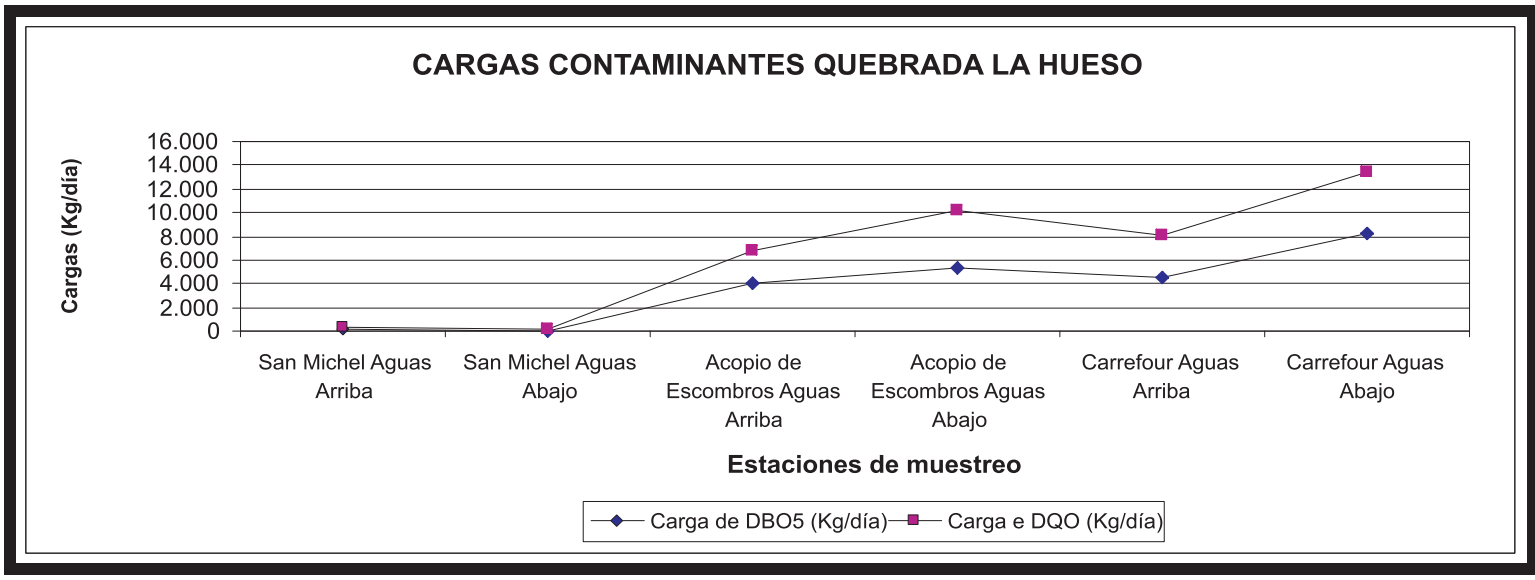

Gráfico 12 . Distribución de la carga de DQO y $\mathrm{DBO}_{5}$ en $\mathrm{Kg} /$ día, quebrada La Hueso

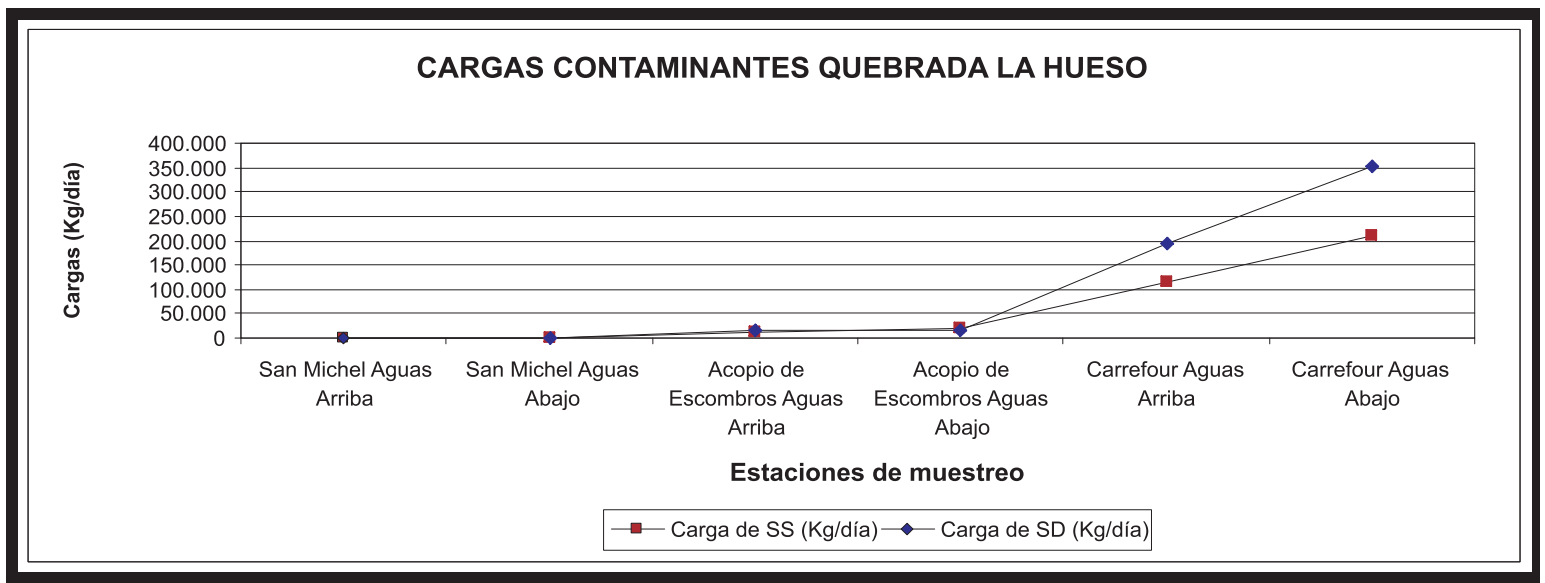

\section{Gráfico 13 . Distribución de la Carga de sólidos suspendidos y disueltos $\mathrm{Kg} /$ día, quebrada La Hueso}


Por las situaciones encontradas a lo largo de la quebrada La Hueso, puede afirmarse que la disposición de escombros y la explotación de materiales pétreos en la parte alta de San Javier es el factor más determinante del deterioro de la microcuenca. Gran parte de los materiales dispuestos y extraídos en las canteras pasan directamente a la corriente, y prueba de ello es la extracción de arenas, canto rodado y triturado que se hace en los barrios Eduardo Santos, Antonio Nariño y Suramericana, con fines comerciales. Aunque podría pensarse que la extracción es benéfica ya que se evita la sedimentación del cauce y colmatación del canal, se genera un efecto contrario, ya que se remueve todo el sustrato, produciendo un incremento en la suspensión de sólidos y de turbiedad. La parte baja de la cuenca, a la altura de la estación Suramericana del Metro, es la que mayores dificultes presenta a lo largo de la cuenca. Aunque este tramo está canalizado, la forma del canal favorece la ocurrencia de desbordamientos e inundaciones. Desde el sector Estadio hasta la Carrera 65, el canal tiene ancho entre los 8 y 6 metros. Pasando dicha carrera, el canal sufre un estrangulamiento, que sumado a la baja pendiente y acumulación de materiales, produce un colapso en el un curso normal de la corriente, saliéndose del canal. Con respecto al vertimiento de escombros y residuos domiciliarios la incidencia es menor, sin embargo, las cargas se incrementan en cada sitio por situaciones muy puntuales como es el caso de los botaderos clandestinos en el Barrio San Michael y cerca de la estación San Javier del Metro. En definitiva y al igual que en la quebrada anterior, las consecuencias directas sobre el río Medellín por las situaciones expuestas, saltan a la vista, contribuyendo en gran medida al deterioro de los fenómenos de transporte y al aumento de las tasa de sedimentación por el arrastre, extracción y depositación en las laderas de los materiales desplazados por la corriente.

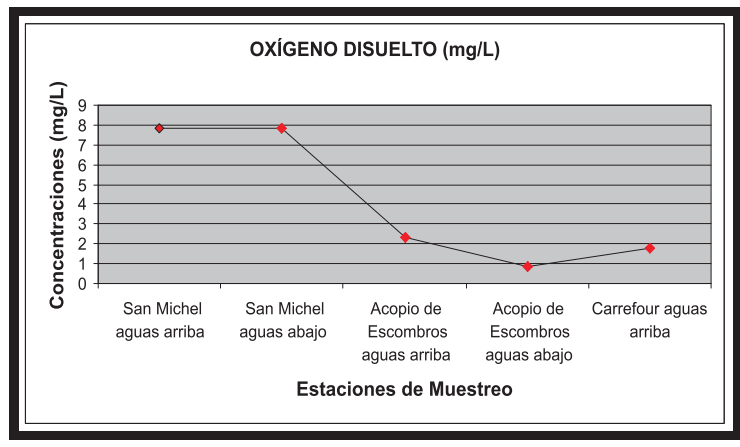

Gráfico14. Oxígeno Disuelto, quebrada La Hueso

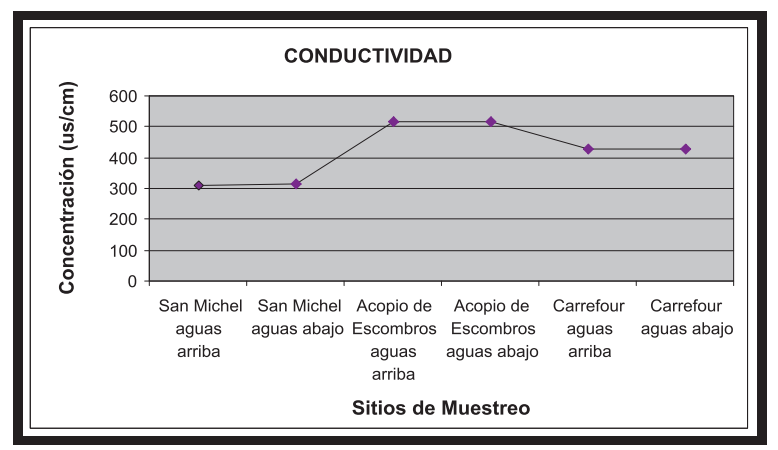

Gráficol5. Conductividad, Quebrada La Hueso 


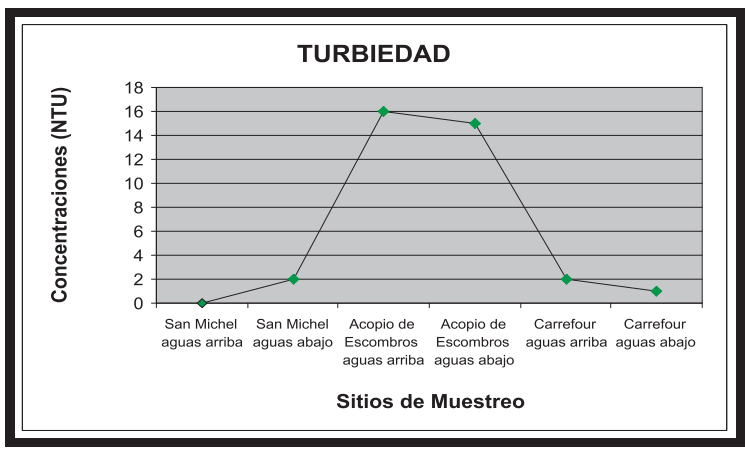

Gráfico16. Turbiedad, quebrada La Hueso

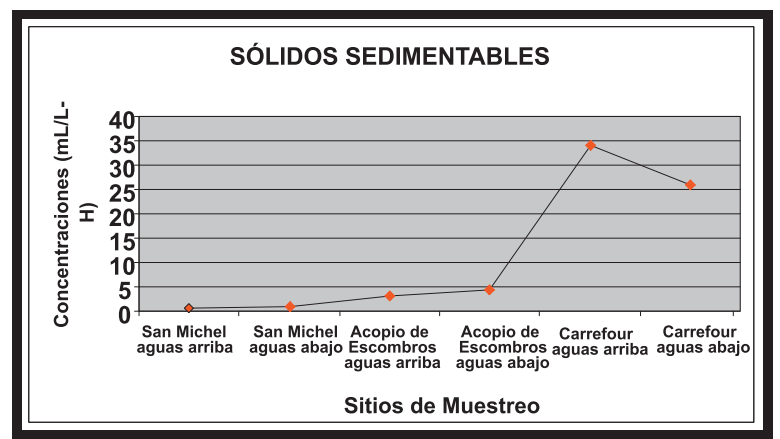

Gráfico17. Sólidos Sedimentables, quebrada La Hueso

Los parámetros analizados previamente, permiten establecer que la quebrada La Hueso presenta una alta intervención y la convierte en una de las más críticas en la región. Aunque el vertimiento de residuos sólidos y de escombros no es su problemática más relevante, también incide en su deterioro. Los residuos domiciliarios solo se presentan en la parte alta, en el sector San Michael y barrio San Javier, cerca la Estación del Metro, a través de botaderos clandestinos que no solo se disponen en las laderas sino también directamente en el lecho. Muchos de éstos se dispersan aguas abajo con ayuda de la corriente. La disposición de escombros a lo largo de la cuenca es mínima, pero el efecto de éstos se ve reflejado en el barrio Santa Lucía ya que allí se encuentra localizado el Centro de acopio de Empresas Varias de Medellín. La disposición de escombros en este sitio no se da directamente en el cauce, pero muchos de los materiales se desplazan a éste por la acción, el viento y escorrentía, aumentando los sólidos. También son muy relevantes en la corriente de la quebrada La Hueso los materiales de tipo flotante, que son trasportados a través del lecho y que tienen bajos niveles de biodegradabilidad. Aunque su aporte en carga orgánica es mínima, la afectación del recurso está relacionada con el deterioro del paisaje y la ocurrencia de impactos negativos desde el punto de vista visual, además de la estrecha relación que tienen con la ocurrencia de taponamientos del cauce desbordamientos e inundaciones.

La explotación de arena y roca en la parte alta y su extracción a lo largo de la quebrada, son las que mayores problemas han causado a la población y a las autoridades municipales. Pese a que se han hecho diferentes estudios desde el punto de vista hidráulico, sanitario y ambiental de la microcuenca en los que se han propuesto soluciones técnicas al problema, son pocas las alternativas efectivas que hayan reparado los inconvenientes que ha causado. La prohibición de la explotación de materiales fue una de las principales alternativas que plantearon los entes de control ambiental y gubernamental para mitigar los efectos sobre la cuenca, sin embargo, esta actividad genera empleo y recursos para la población, razones de peso valederos para autorizarla. Se ha pensado en la construcción de estructuras hidráulicas que retengan arenas y 
rocas desde sus sitios de origen y en parte alta de la quebrada, sin embrago, se requieren altas sumas de dinero para poder ejecutar las obras.

La quebrada La Hueso genera grandes dificultades en las épocas de invierno, pues es recurrente su desbordamiento en el sector Eduardo Santos (parte alta) y Suramericana (parte baja). Esta situación conlleva a sobrecostos en el servicio de mantenimiento y aseo para la administración municipal y las EPSA's, ya que requiere de personal experto para la adecuación de los canales afectados y de cuadrillas adicionales de aseo para recolectar y disponer adecuadamente los materiales y residuos que se generan por las altas crecientes. El río Medellín también se ve afectado por las condiciones sanitarias e hidráulicas que presenta La Hueso. Aunque muchos de los materiales de arrastre se extraen previamente antes de la desembocadura, algunos de ellos pasan al canal del río aumentando todos los parámetros estudiados, especialmente los sólidos y la turbiedad.

Resumiendo las situaciones encontradas en las quebradas objeto de estudio, puede establecerse que las cargas proporcionaron una idea general del estado actual de las microcuencas, y esta evaluación resulta de extrema importancia, ya que permite disponer de una valiosa herramienta de trabajo, a través de la cual es posible identificar y establecer prioridades de gestión, en el marco de la formulación de los planes de ordenamiento de las cuencas hidrográficas y los planes sectoriales de la economía local. Los resultados podrán evaluar de forma sistemática, las tendencias que se manifiestan en la calidad de la región, como resultado de la aplicación de un conjunto de alternativas de solución dirigidas a mitigar los efectos causados por el vertimiento de aguas residuales y residuos sólidos hacia diversos cuerpos receptores.

\subsection{Residuos sólidos, materiales de arrastre y escombros vertidos en las microcuencas.}

En este ítem se tipificaron y cuantificaron los residuos sólidos, escombros y materiales de arrastre producto de la explotación minera, encontrados en los sitios más próximos de las estaciones de monitoreo, como laderas y cauces.

\subsubsection{Granulometría}

La granulometría realizada a los materiales (escombros y materiales de arrastre) encontrados en el lecho y laderas de las quebradas estudiadas, tienen por finalidad determinar en forma cuantitativa la distribución de las partículas de acuerdo con su tamaño, de tal manera de evaluar si influyen o no, sobre la calidad física y química de éstas y del río Medellín. De manera general y de acuerdo con las inspecciones de campo, se encontró que existe gran heterogeneidad con el 
tipo y tamaño de los materiales hallados. En los lechos y laderas se observan materiales como escombros producto de demoliciones y remodelaciones, materiales de arrastre como tierras, arenas y rocas de diferentes tamaños. Los sitios en los cuales se tomaron las muestras, corresponden a puntos recurrentes de vertimiento de escombros o arrastre de materiales, identificados en los recorridos de campo mencionados en puntos anteriores.

\subsubsection{Granulometría Quebrada La García}

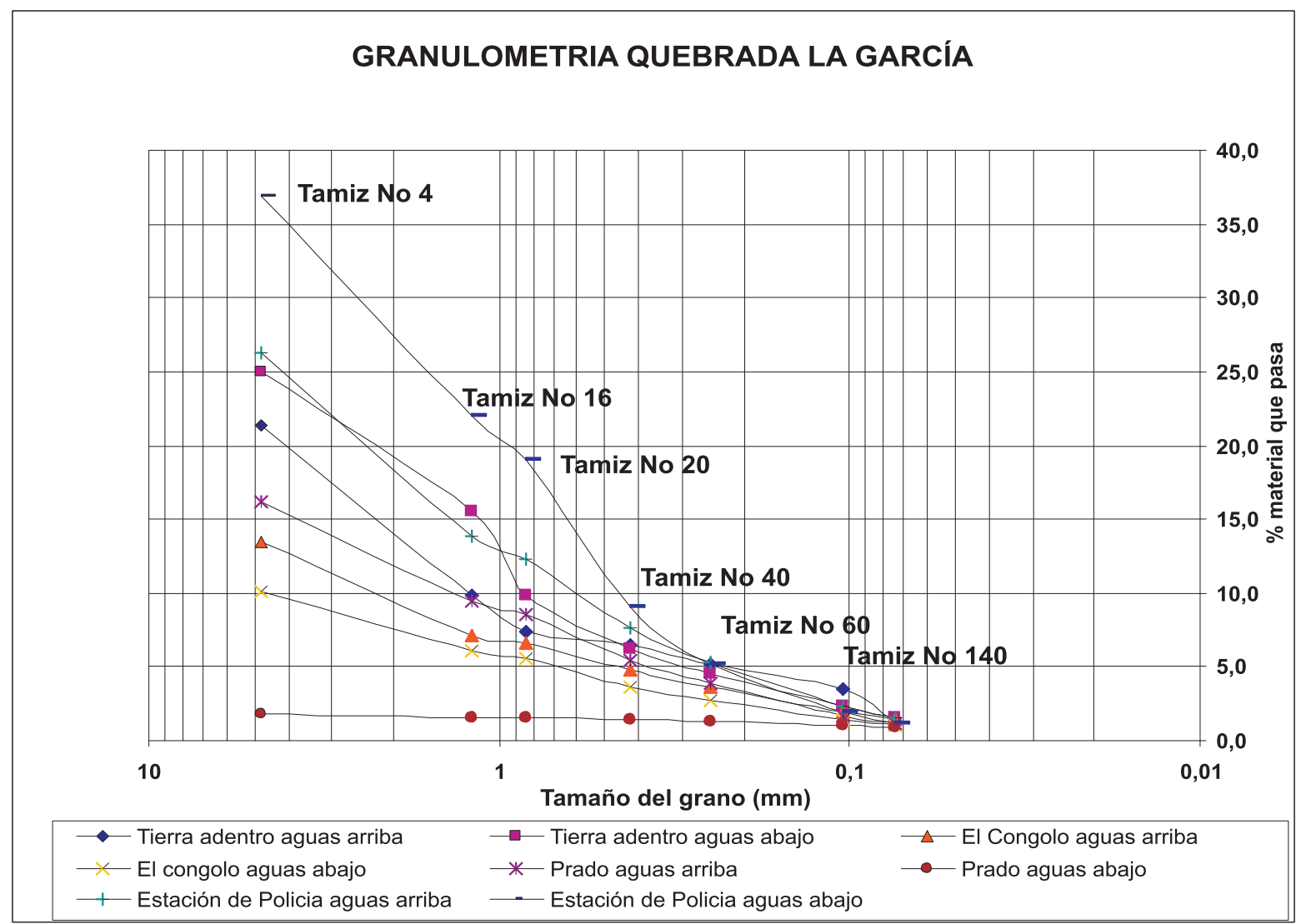

Figura 2 Curva granulométrica quebrada La García

La muestra los diferentes tamaños de los materiales inertes (escombros y de arrastre) presentes en cada una de las estaciones de monitoreo de la quebrada La García. Como se ha mencionado a lo largo de los análisis de resultados, y especialmente en el ítem de cargas de sólidos, la quebrada La García presenta una alta intervención producto del vertimiento de escombros sobre las laderas y cauce como por la explotación de agregados pétreos en la parte alta. Dichos materiales se van depositando a lo largo de la microcuenca en función de factores 
como pendiente, caudal, velocidad, tipo de canal, estado del tiempo, entre otros. La tendencia es que para los tramos en los cuales se presenta menor turbulencia, los materiales más frecuentes son los que tienen menor tamaño (arenas, gravas, triturado), mientras que en los tramos de mayor caudal se presentan rocas y bloques de tamaños considerables.

Para el sector Tierra Adentro, correspondiente a la parte alta de la quebrada, los materiales predominantes en los lechos y márgenes son arenas, gravas y rocas de mediano tamaño; el bajo caudal y poca turbulencia de la corriente, favorecen la depositación de éstos sobre áreas próximas al cauce, permitiendo su extracción con fines comerciales por parte de los habitantes del sector. Hacia la parte media, en los barrios El Congolo y Prado, las altas pendientes y velocidades, favorecen el arrastre de materiales de mayor tamaño como rocas y escombros fracturados; muchos de ellos se quedan represados en las márgenes, debido a que el cauce se conserva de forma natural y a los bajos caudales que se dan en épocas de verano, mientras que los más livianos siguen su trayecto, especialmente en los tramos en los cuales el cauce está canalizado. Cuando se presentan altas crecientes, se genera resuspensión de materiales debido a la alta turbulencia, lo cual ocasiona un aumento de sólidos suspendidos a lo largo de toda la microcuenca. Hacia las partes más bajas, antes de la desembocadura al río Medellín, la depositación de suelos, arenas y rocas se da en mayor proporción debido al cambio en la forma del canal; el ancho se disminuye y sus márgenes pasan a tener placas en concreto.

\subsubsection{Granulometría Quebrada La Hueso}

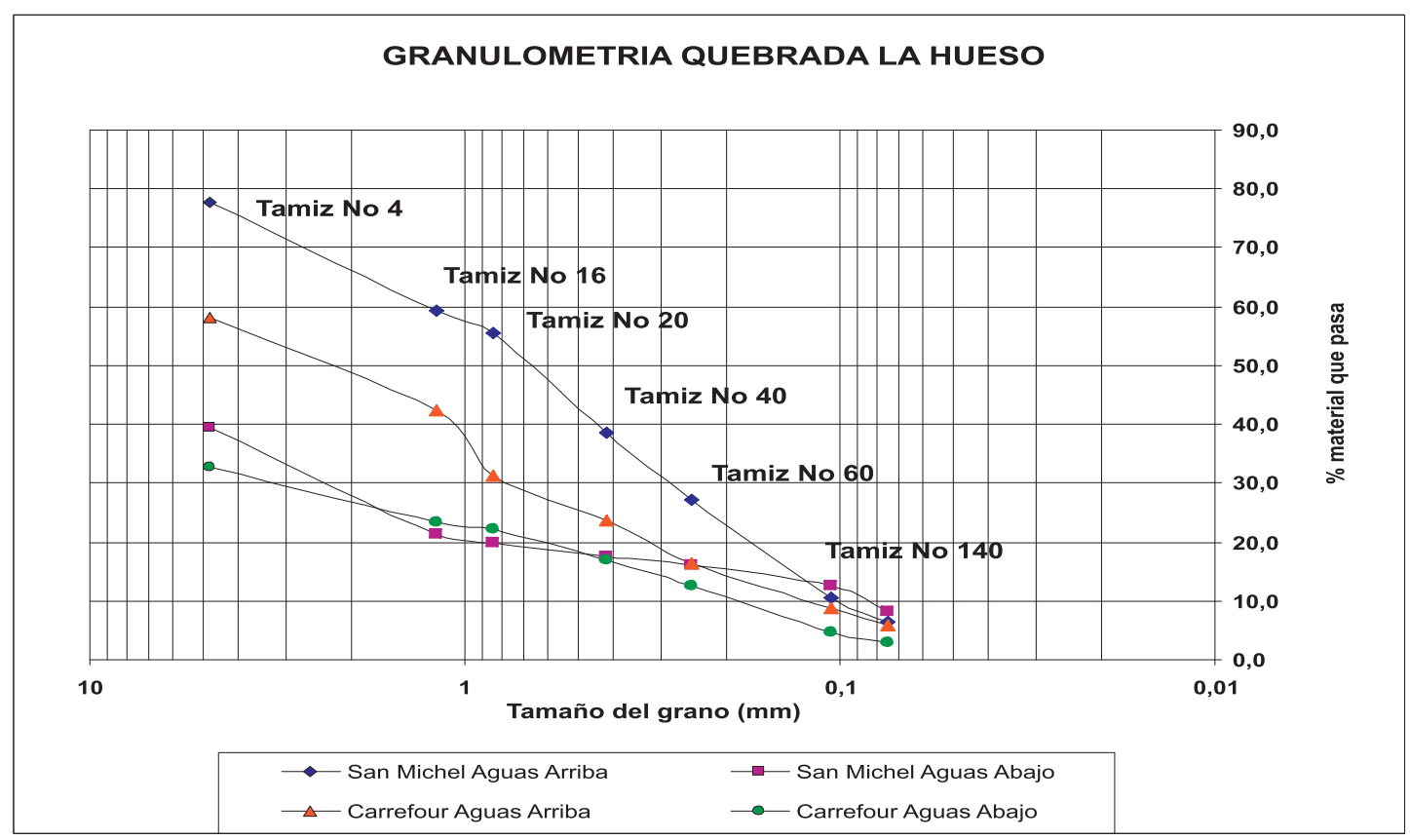

Figura 3 . Curva granulométrica quebrada La Hueso 
La quebrada La Hueso presenta una tipología de materiales diferentes a la quebrada La García, ya que se observan en mayores proporciones arenas, suelos y agregados pétreos y muy pocos escombros provenientes de demolición y remodelación. En esta quebrada solo se tomaron muestras en las estaciones San Michael y Carrefour, en la cuales se presentaban materiales de arrastre en las laderas y en el cauce, que permitieron clasificarse a partir de la granulometría. En la estación Acopio de escombros aguas arriba y aguas abajo, no se tomaron muestras para la clasificación granulométrica debido a que las laderas se encuentran completamente canalizadas en forma trapezoidal y con ancho de aproximadamente 2 metros; la pendiente y la velocidad en este tramo ocasiona que los materiales de arrastre se depositen en zonas mas bajas, como es el caso de la estación Carrefour.

La tendencia de los materiales depositados en las laderas y lecho de la quebrada La Hueso está relacionada con sólidos que le aportan suspensión al agua, transportados por la corriente debido a las altas turbulencias. Cuando el caudal baja, se observa la sedimentación de éstos, favoreciendo su extracción manual, como en el caso de los barrios Eduardo Santos y Antonio Nariño, parte alta de la microcuenca. El punto mas crítico de acumulación de materiales se da en la estación Carrefour aguas abajo, en el sector de Suramericana. Desde el barrio San Javier hasta la estación en mención, el cauce viene canalizado con anchos que oscilan entre los 2 y 10 metros aproximadamente, pero como se presenta un estrechamiento, muchos de éstos no pueden ser arrastrados por la corriente quedándose retenidos en el sitio. La acumulación de materiales genera graves inundaciones en el barrio Suramericana y Naranjal, sumado a las pérdidas materiales y sobrecostos en el servicio de mantenimiento y aseo por la limpieza y recolección de objetos desbordados. En el sitio también se encuentran los valores más altos de sólidos en suspensión debido a la alta sedimentación que allí se presenta. De manera general, puede concluirse que la quebrada La Hueso es una microcuenca que se ve afectada en un alto porcentaje por el transporte de materiales producto de la explotación de arenas y disposición de escombros en su parte alta. Es una quebrada torrencial, capaz de conducir todo tipo de sedimentos. En los tramos de baja pendiente y con amplios canales, la acumulación es mayor, observándose simetría en los objetos, mientras que en los de pendiente alta, la heterogeneidad es mayor, debido a las facilidades en el transporte por la corriente. 


\subsubsection{Granulometría Quebrada La Iguaná}

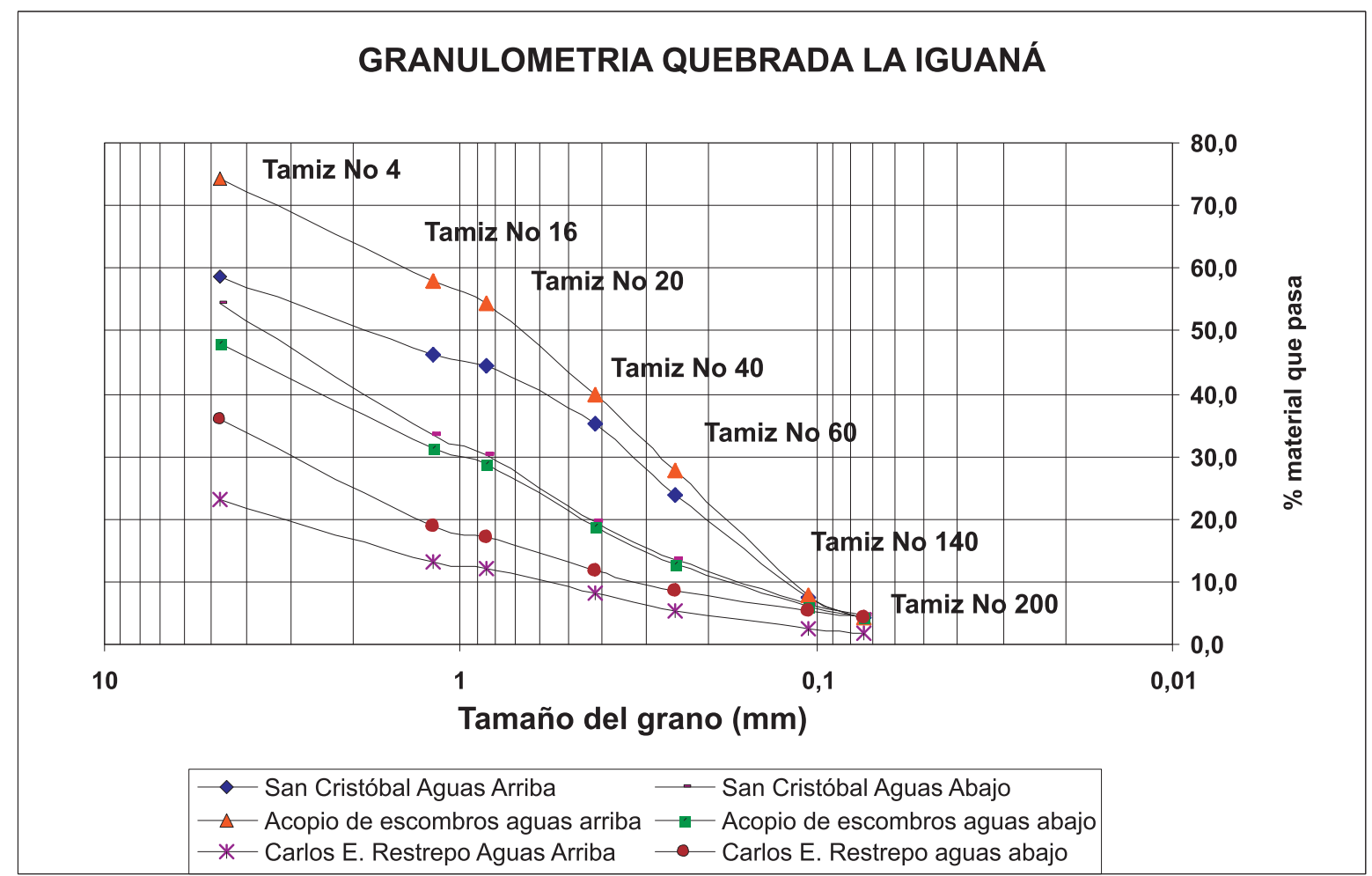

Figura 4 . Curva granulométrica quebrada La Iguaná

La lguaná se caracteriza por ser una quebrada receptora de escombros, ya que algunas de las comunidades cercanas, la han convertidos en botaderos clandestinos, depositando sobre su cauce y laderas materiales provenientes de excavación y demolición. También presenta alguna influencia por materiales de arrastre, pues en su parte alta se explotan materiales para la construcción como arenas y triturados, así como la disposición final de remantes del proceso de fabricación de ladrillos, en la ladrillera San Cristóbal. De manera particular, los materiales más representativos son los que presentan mayores tamaños, como es el caso de ladrillos, cuescos de concreto, mortero y cerámicos fracturados, madera, pedazos de plásticos, dispuestos inadecuadamente en los cauces por parte de las comunidades cercanas debido a múltiples razones, entre ellas por el desconocimiento de la existencia de rutas especiales para la recolección escombros y al los pocos recurso para el pago de dicho servicio.

En definitiva, los procesos de depositación y acumulación de sedimentos a lo largo de la microcuenca La lguaná están influenciados básicamente por diferentes factores entre ellos la configuración del terreno y las características del canal. Desde la zona rural, en el corregimiento 
de San Cristóbal, hasta la parte media, en el barrio El Pesebre, se dan altas pendientes y encañonamientos que favorecen el flujo de materiales abruptamente hacia las partes mas bajas. Prueba de ello, es la gran cantidad de rocas, arenas y gravas que se encuentran en este último barrio, por ser una zona de menor pendiente con respecto a la anterior; además de esto, se observa una ampliación prominente del canal, así como la presencia de un azud que permite el control del caudal y el paso de sedimentos. Una situación similar se presenta en el Barrio San Germán, entre las carreras 70 a 73, en el cual se amplia nuevamente el canal, baja la pendiente y la velocidad, situación que permite la retención y acumulación de materiales de playa de diferentes formas y tamaños. Las islas que se forman en dicho sitio ayudan a que gran parte de éstos se extraigan manual y mecánicamente, incrementando aun más la sedimentación y colmatación del cauce; también se tiene una estructura hidráulica aprovechando la diferencia de pendientes, que regula el caudal y el paso de sólidos, hacia agua abajo. Dichos escenarios son las causas más relevantes de los valores de sólidos suspendidos y sedimentables hallados en la lguaná, que pasan a ser parte de la corriente y desembocan en el sector de Carlos E Restrepo sobre el Río Medellín, afectando notoriamente su calidad e hidráulica.

De acuerdo con los resultados mostrados anteriormente, para cada una de las granulometrías de las quebradas La García, La Hueso y La lguaná, puede concluirse que la gran mayoría de los materiales presentes en las laderas y cauces, presentan tamaños superiores a los 4 centímetros de características y procedencias heterogéneas como demolición y remodelación para los escombros, y de la explotación de materiales como canto rodado, triturado y arenas. Los análisis de aguas son el reflejo de la afectación que causan dichos materiales sobre el recurso y sobre las características hidráulicas del cauce. A simple vista puede apreciarse la gran cantidad de sólidos suspendidos en el agua causando altas turbiedades. Otro problema que agudiza los conflictos ambientales y sociales de las microcuencas, es que los materiales inertes tipo escombros y los provenientes de canteras, areneras, como es el caso de las quebradas mencionadas, provoca inundaciones, deslizamientos y destrucción de bienes inmuebles, debido a la torrencialidad, caudal y velocidad de las corrientes. La corriente y los materiales que ésta arrastra a su paso, provocan socavación y erosión de las laderas, volviendo a viviendas, árboles y cualquier estructura, vulnerables a derrumbamientos. Los materiales tamizados en la mayoría de las estaciones de las quebradas objeto de estudio, son concordantes con los tipos de escombros caracterizados en los cauces de cada una de ellas, cuyos resultados serán expuestos en ítems posteriores. Éstos influyen considerablemente sobre la calidad del agua aportando gran cantidad de sólidos en suspensión, que le dan un aspecto turbio y desagradable al recurso, además, de que son los causantes en un alto porcentaje de los procesos de sedimentación y socavación de márgenes y lechos, en especial de aquellos que no se encuentran canalizados. 


\subsubsection{Caracterización de residuos}

Posterior a los recorridos de campo realizados en cada de las microcuencas, se localizaron los puntos mas críticos de vertimiento de escombros y residuos sólidos domésticos, en las cuales se realizó una caracterización para determinar cantidades y porcentajes en peso y volúmenes. Las cantidades de residuos y escombros encontrados son considerables, en especial en las microcuencas La García y La lguaná, evidenciando materiales que en su mayoría son de carácter reciclable. Para el caso de los escombros, las características de los materiales corresponden a ladrillos y cuescos de concreto, cerámicos, arenas y suelos de diferente granulometría. Es importante aclarar que dependiendo de la cantidad de residuos encontrados en los alrededores de las microcuencas en mención, se tomaron muestras de peso variable, que oscilan entre los 30 y 50 kilogramos. Estos valores no se tomaron teniendo en cuenta un diseño estadístico, y podrían considerarse subjetivos, sin embargo, el muestreo fue cuantitativo, tomando extractos de todos los materiales presentes en la masa de residuos dispuestos en las laderas y en las orillas. A continuación se describen los tipos y cantidades de residuos caracterizados:

\subsubsection{Cuantificación y porcentaje en peso de los residuos quebrada La Hueso} En la, se presenta un estimativo de los materiales de arrastre que se encuentran en cada una de las estaciones de monitoreo.

\section{Tabla 3 .Cuantificación de materiales de arrastre en la quebrada La Hueso}

\begin{tabular}{|c|c|c|c|c|}
\hline Ítem & $\begin{array}{c}\text { San Michael } \\
\text { aguas arriba }\end{array}$ & $\begin{array}{c}\text { San Michael } \\
\text { aguas abajo }\end{array}$ & $\begin{array}{c}\text { Carrefour } \\
\text { aguas arriba }\end{array}$ & $\begin{array}{c}\text { Carrefour } \\
\text { aguas abajo }\end{array}$ \\
\hline Peso muestra $(\mathrm{Kg})$ & 30,00 & 30,00 & 50,00 & 50,00 \\
\hline Volumen muestra $\left(\mathrm{m}^{3}\right)$ & 0,02 & 0,02 & 0,03 & 0,03 \\
\hline Densidad $\left(\mathrm{Kg} / \mathrm{m}^{3}\right)$ & $1.666,67$ & $1.621,62$ & $1.612,90$ & $1.666,67$ \\
\hline Área total de disposición $\left(\mathrm{m}^{2}\right)$ & 12 & 18,3 & 25 & 32 \\
\hline Altura promedio $(\mathrm{m})$ & 0,5 & 0,3 & 0,4 & 0,4 \\
\hline Peso Total (ton) & $\mathbf{1 0 , 0 0}$ & $\mathbf{8 , 9 0}$ & $\mathbf{1 6 , 1 3}$ & $\mathbf{2 1 , 3 3}$ \\
\hline
\end{tabular}

De acuerdo con los datos de la, los valores muy puntuales, encontrados en épocas de lluvias de variada intensidad. Para las épocas secas la cantidad de materiales puede aumentar debido a los fenómenos de sedimentación y depositación ya descritos.

De acuerdo con los análisis de aguas mostrados y analizados previamente, la intervención sobre la calidad del recurso hídrico en las estaciones mencionadas es alta debido a la gran cantidad de sólidos en suspensión y dilución, que le aportan turbiedad y conductividad al agua, y que provienen básicamente de los materiales de arrastre que se explotan en la parte alta de la microcuenca en las escombreras Terrígenos y ESSA y canteras como agregados San Javier. A lo 
largo de la quebrada, y en especial sobre la carrera 65 con calle $48^{a}$, a la altura de la estación Suramericana del Metro, permanecen de manera continua personas extrayendo el material arrastrado por la corriente para su posterior comercialización, lo cual incide en gran proporción sobre la capacidad hidráulica y calidad del agua. Esta es una zona de baja pendiente y de velocidad media, en la que se presentan represamientos de materiales de arrastre permitiendo su fácil extracción por particulares. En periodos de invierno como el ocurrido desde el mes de agosto y septiembre del presente año y de años anteriores, la quebrada ha presentado desbordamientos, generando graves pérdidas económicas al sector de Naranjal y Suramericana, y sobrecostos a la Administración Municipal por la limpieza y remoción del piedras, lodos, material vegetal y todo tipo de residuos sólidos.

\subsubsection{Cuantificación y porcentaje en peso de los residuos quebrada La Iguaná}

\section{Tabla 4 . Cuantificación de materiales de arrastre y escombros en la quebrada La Iguaná}

\begin{tabular}{|c|c|c|c|c|c|c|}
\hline \multirow[b]{2}{*}{ Ítem } & \multirow{2}{*}{\begin{tabular}{|c|}
$\begin{array}{c}\text { Material de } \\
\text { Arrastre }\end{array}$ \\
$\begin{array}{c}\text { San Cristóbal } \\
\text { aguas arriba }\end{array}$
\end{tabular}} & \multicolumn{5}{|c|}{ Escombros } \\
\hline & & $\begin{array}{c}\text { San } \\
\text { Cristóbal } \\
\text { aguas } \\
\text { arriba }\end{array}$ & $\begin{array}{c}\text { Acopio de } \\
\text { escombros } \\
\text { aguas arriba }\end{array}$ & $\begin{array}{c}\text { Acopio de } \\
\text { escombros } \\
\text { aguas abajo }\end{array}$ & $\begin{array}{c}\text { Carlos E. } \\
\text { Restrepo } \\
\text { aguas arriba }\end{array}$ & $\begin{array}{c}\text { Carlos E } \\
\text { Restrepo } \\
\text { aguas abajo }\end{array}$ \\
\hline $\begin{array}{c}\text { Peso muestra } \\
(\mathrm{Kg})\end{array}$ & 40,00 & 50,00 & 70,00 & 50,00 & 35,00 & 40,00 \\
\hline $\begin{array}{c}\text { Volumen } \\
\text { muestra }\left(\mathrm{m}^{3}\right)\end{array}$ & 0,018 & 0,04 & 0,05 & 0,03 & 0,028 & 0,025 \\
\hline $\begin{array}{c}\text { Densidad } \\
\left(\mathrm{Kg} / \mathrm{m}^{3}\right)\end{array}$ & 2222,2 & 1.250 & 1.400 & 1.613 & 1.250 & 1.600 \\
\hline $\begin{array}{l}\text { Área Total de } \\
\text { disposición } \\
\left(\mathrm{m}^{2}\right)\end{array}$ & 45 & 105 & 24,5 & 9,5 & 17 & 8 \\
\hline $\begin{array}{c}\text { Altura } \\
\text { promedio }(\mathrm{m})\end{array}$ & 0,7 & 0,6 & 0,75 & 0,4 & 0,7 & 1,2 \\
\hline $\begin{array}{l}\text { Peso Total } \\
\text { (ton) }\end{array}$ & 70,00 & 78,75 & 25,73 & 6,13 & 14,88 & 15,36 \\
\hline
\end{tabular}

La quebrada La lguaná presenta una tipología de residuos muy diferente a la quebrada anterior, ya que las condiciones socioeconómicas de los barrios por donde transita son más bajos, perteneciendo a los estratos 1, 2 y 3 . Dichas circunstancias están asociadas a bajos niveles educativos, culturales y poco sentido de pertenencia frente a su entorno, que generan prácticas inadecuadas de disposición de residuos ordinarios y escombros en lotes baldíos, parques, vías, laderas y cauces de cuerpos de agua. 
Prueba de ello son los resultados presentados en la, caracterizados en los sitios más próximos del cauce. En la estación San Cristóbal predominan materiales inertes provenientes de demoliciones y remodelaciones como ladrillo, cuescos de concreto, mortero, entresuelos, tejas, entre otros. También se observaron materiales producto de la explotación aluvial con materiales como canto rodado y arenas de diverso tamaño. En la estación Acopio de Escombros se presentan condiciones diferentes a los anteriores puntos de monitoreo, ya que es un lugar en el cual se extraen permanentemente materiales para construcción como arenas, triturado y canto rodado para su posterior comercialización. Dicha extracción se presenta especialmente en época de verano, pues el nivel de la quebrada baja considerablemente. En el barrio La lguaná se localizan los puntos de monitoreo Carlos E. Restrepo, en los cuales se presenta una invasión directa del cauce, debido a la gran cantidad de viviendas asentadas a menos de 15 metros. Esta invasión ocasiona que se dispongan permanentemente residuos de diferente naturaleza, lo que conlleva a desbordamientos y represamientos continuos.

\subsubsection{Cuantificación y porcentaje en peso de los residuos quebrada La García}

Los residuos sólidos caracterizados en la quebrada La García presentan alta variabilidad, que están en función de la zona por donde transita. La parte alta presenta alta influencia de canteras y de sitios de extracción de materiales, la parte media se ve afectada por la disposición de escombros a través de botaderos clandestinos, y la parte baja es una sumatoria de las tres situaciones, arrastre de materiales, disposición de escombros y residuos domésticos.

\section{Tabla 5 . Cuantificación de residuos domiciliarios y material de arrastre en la quebrada La García}

\begin{tabular}{|c|c|c|c|c|}
\hline \multirow{2}{*}{ Ítem } & \multicolumn{3}{|c|}{ Escombros } & $\begin{array}{c}\text { Residuos } \\
\text { domiciliarios }\end{array}$ \\
\cline { 2 - 5 } & $\begin{array}{c}\text { Tierra Adentro } \\
\text { aguas arriba }\end{array}$ & $\begin{array}{c}\text { Tierra Adentro } \\
\text { aguas abajo }\end{array}$ & $\begin{array}{c}\text { Estación de } \\
\text { Policía aguas } \\
\text { abajo }\end{array}$ & $\begin{array}{c}\text { Prado aguas } \\
\text { abajo }\end{array}$ \\
\hline Peso muestra $(\mathrm{Kg})$ & 50,00 & 50,00 & 50,00 & 30,00 \\
\hline Volumen muestra $\left(\mathrm{m}^{3}\right)$ & 0,030 & 0,025 & 0,032 & 0,22 \\
\hline Densidad $\left(\mathrm{Kg} / \mathrm{m}^{3}\right)$ & 1666,7 & 2000,0 & 1562,5 & 136,36 \\
\hline Área Total de disposición & 22 & 18,5 & 20 & 17 \\
\hline Altura promedio (m) & 0,5 & 0,5 & 0,4 & 0,8 \\
\hline Peso Total (ton) & $\mathbf{1 8 , 3 3}$ & $\mathbf{1 8 , 5 0}$ & $\mathbf{1 2 , 5 0}$ & $\mathbf{1 , 8 5}$ \\
\hline
\end{tabular}




\section{Tabla 6 . Cuantificación de escombros en la quebrada La García}

\begin{tabular}{|c|c|c|c|c|c|}
\hline Ítem & $\begin{array}{c}\text { El Congolo } \\
\text { aguas arriba }\end{array}$ & $\begin{array}{c}\text { El Congolo } \\
\text { aguas abajo }\end{array}$ & $\begin{array}{c}\text { Prado aguas } \\
\text { arriba }\end{array}$ & $\begin{array}{c}\text { Prado aguas } \\
\text { abajo }\end{array}$ & $\begin{array}{c}\text { Estación de } \\
\text { Policía aguas } \\
\text { arriba }\end{array}$ \\
\hline Peso muestra $(\mathrm{Kg})$ & 30,00 & 50,00 & 30,00 & 30,00 & 50,00 \\
\hline Volumen muestra $\left(\mathrm{m}^{3}\right)$ & 0,037 & 0,028 & 0,03 & 0,028 & 0,030 \\
\hline Densidad $\left(\mathrm{Kg} / \mathrm{m}^{3}\right)$ & 811 & 1.786 & 1.000 & 1.071 & 1.667 \\
\hline $\begin{array}{c}\text { Área Total de } \\
\left.\text { disposición (m }{ }^{2}\right)\end{array}$ & 14 & 300 & 9 & 17 & 48 \\
\hline Altura promedio $(\mathrm{m})$ & 0,8 & 1,6 & 0,7 & 0,4 & 0,8 \\
\hline Peso Total (ton) & $\mathbf{9 , 0 8}$ & $\mathbf{8 5 7 , 1 4}$ & $\mathbf{6 , 3 0}$ & $\mathbf{7 , 2 9}$ & $\mathbf{6 4 , 0 0}$ \\
\hline
\end{tabular}

Las tablas anteriores muestran la estimación de los residuos dispuestos en cada uno de los monitoreos de la quebrada La García. Se reitera que son valores puntuales, que no reflejan situaciones periódicas, ya que la variabilidad en las prácticas de disposición no es constante en el tiempo y depende de muchos factores entre ellos los económicos y sociales.

La estación Tierra Adentro ubicada en la parte alta de la microcuenca, no presenta vertimiento de residuos domiciliarios ni escombros, pero si se encuentran sobre las laderas, materiales de arrastre como triturado, rocas de mediano y gran tamaño, arenas finas y gruesas, tanto aguas arriba como aguas abajo. La estación El Congolo presenta un botadero clandestino de escombros, el cual se limpia continuamente por parte de la empresa de aseo del municipio de Bello, de acuerdo con los requerimientos hechos por la comunidad, sin embargo, los cocheros y algunas personas de la zona convierten el sitio en un botadero permanente, pese a la prohibición de hacerlo.

Finalmente, el punto de muestreo cerca de la desembocadura del río Medellín, corresponde a la estación de Policía de Bello. En este sitio, sobre un costado del puente de la carrera 50, en la margen derecha de la quebrada, se arrojan permanentemente escombros por los cocheros del municipio. Es una situación que ha sido identificado por las autoridades respectivas, ya que existe la restricción de arrojar escombros; sin embargo, el problema persiste, pese a la advertencia de multas y sanciones.

\subsection{Evaluación de causas}

Comprender el accionar humano implica considerar una serie de cuestiones de carácter histórico, económico, social, cultural y político que se interrelacionan para conformar una compleja trama, a través de la cual se explican las condiciones estructurales determinantes de 
las problemáticas ambientales y de marginalidad económica y social que se observa en las microcuencas objeto de la presente investigación. Desde esta perspectiva, se ha venido analizando a lo largo de la investigación, aspectos relacionados con las condiciones del medio natural, las características socioeconómicas, las formas de apropiación y uso de los recursos naturales, el comportamiento social de las comunidades aledañas a las microcuencas y el rol que el sector público ha jugado en el devenir de estos espacios.

\subsubsection{Perspectiva socioeconómica}

Es innegable, que las causas más cercanas a las problemáticas ambientales actuales, y más específicamente a las disposiciones inadecuadas de residuos, están asociados a las bajas condiciones socioeconómicas de la población. Las comunidades con menores ingresos económicos carecen de servicios públicos domiciliarios básicos, coberturas educativas y de salud, que les permita tener una calidad de vida aceptable. Dichas condiciones se asocian a un alto deterioro del entorno y presión sobre los recursos naturales, de tal forma de suplir sus necesidades básicas como alimentación, vivienda y recreación y garantizar unas condiciones mínimas de supervivencia.

Bajo un contexto social, las poblaciones mas pobres son las que menos presentan niveles de escolaridad, que les permita tener un nivel educativo acorde a la vanguardia mundial y al desarrollo tecnológico que hoy se presenta. Sus costumbres y tradiciones, sumado al poco sentido de pertenencia hacia su entorno, los lleva a generar alta degradación sobre el medio ambiente, poniendo en riesgo su integridad física. Bajo esta perspectiva, las principales causas que generen disposiciones inadecuadas de residuos sólidos y escombros son:

- Incremento acelerado de la población: Bajo esta premisa puede considerase que el incremento acelerado de la población repercute sobre el deterioro ambiental, ya que las ciudades tienen una densidad poblacional mas alta por el desplazamiento desde las zonas rurales, sobrecargando los sistemas de transporte, salud, comunicaciones y saneamiento.

- Pobreza: La pobreza suele ir acompañada de desempleo, malnutrición, analfabetismo, bajo nivel social, riesgos ambientales y un acceso limitado a servicios sociales y sanitarios incluidos los servicios de salud reproductiva, que a su vez incluyen la planificación de la familia.

- Bajos Niveles Educativos: Pese a estos esfuerzos y a los programas que aseguren educación gratuita para las poblaciones de escasos recursos, aún se presentan bajos niveles educativos, que repercuten directamente en subdesarrollo, decrecimiento de la economía y un aumento del deterioro ambiental.

- Facilidad de evacuación de los sitios de generación: Las comunidades de bajos recursos asentadas en zonas de invasión y las que se encuentran más próximas a los cauces de las 
fuentes superficiales de agua, por facilidad en tiempo y esfuerzo en el desplazamiento hasta el sitio de recolección, optan por arrojar desde las partes traseras o ventanas de la vivienda, los residuos directamente en el lecho, generando los efectos ya expuestos.

- Poco sentido de pertenencia y conciencia sobre el deterioro ambiental: El grado de sensibilidad y sentido de pertenencia sobre el deterioro ambiental es bajo, importándoles poco su bienestar y calidad de vida que se reduce por condiciones sanitarias y ambientales adversas.

- Carencia de recursos económicos para el pago de servicios públicos: Los bajos recursos económicos para el pago de servicios públicos también es una de las principales causas de vertimientos de residuos a los cuerpos de agua, especialmente cuando se habla de escombros.

\subsubsection{Perspectiva técnica}

Los países en vía de desarrollo, como en el caso del país, presentan estructuras muy precarias para la prestación oportuna del servicio de aseo, que sólo incluye el componente de recolección y no los relacionados con la generación, presentación, tratamiento y disposición final de los residuos sólidos. A partir de la expedición del Decreto 1713 de 2002 del MAVDT, se comenzó a hablar de planes de Gestión Integral, cuyo fin es lograr una sinergia de todos los componentes del manejo de los residuos sólidos, de tal forma que se vea reflejado en un mejor manejo desde la fuente generadora y en una recolección eficiente, tratamientos y disposiciones acordes con la naturaleza de los mismos, y en el mejoramiento de las condiciones ambientales y sanitarias de la región. A pesar de contar con dichos planes, el servicio de aseo sólo se enfoca en la región desde la recolección y disposición final, dejando a un lado los demás componentes, que deben ser asumidos por cada generador en función la naturaleza de los residuos.

- Interrupción del servicio estándar de aseo: aunque las empresas de aseo por norma deben tener frecuencias y horarios de recolección establecidos en cada barrio para los residuos domiciliarios, existen factores que repercuten en la variación temporal de la frecuencia como son la topografía, estado de las vías, clima, orden público de la zona y estado mecánico de los vehículos.

- Bajas frecuencias en zonas por encima del perímetro sanitario o periurbanas: Las bajas coberturas en los sitios que no pertenecen al perímetro urbano se dan por múltiples razones, como las expuestas en el ítem anterior, además del costo que le acarrea a la empresa de aseo desplazar los vehículos a zonas apartadas y llevar los residuos hasta el sitio de disposición final autorizado.

- Desconocimiento de los días y frecuencias de entrega de residuos: Algunas personas desconocen las frecuencias y horarios de recolección de los residuos domiciliarios en los barrios, razón por la cual se presentan en sitios y horarios diferentes a los establecidos, 
exponiendo los residuos a la descomposición favorecida por los factores climáticos, proliferación de insectos, roedores y aves de rapiña, así como el escudriñamiento de perros y gatos que buscan alimento.

- Carencia de sitios autorizados para la disposición final: Aunque este no es el caso actual de la región, la carencia de sitios de disposición final autorizados (rellenos sanitarios), es una de las principales causas de la problemática analizada.

\subsubsection{Desde el punto de vista legal}

La escasa coordinación efectiva en la formulación de planes, programas y proyectos de nivel nacional, departamental y municipal, con la debida armonización y compatibilización entre ellos, es una de las causas de la persistencia de problemas organizacionales, técnicos y operativos para resolver sanitaria y ambientalmente la problemática de los residuos sólidos. El país y región aunque cuentan con Autoridades Ambientales y organismos de control que se encargan de velar por una calidad ambiental favorable, se presentan debilidades en la estructura institucional formal, que normalice, controle y vigile todo lo relacionado con la gestión de los residuos sólidos, debido al escaso recurso humano y financiero para cubrir a todos los generadores y ejecutar todas las actividades en pro de solucionar la problemáticas relacionados con éstos.

- Desconocimiento de normas y políticas: la comunidad en general desconoce las normas en materia de residuos sólidos, así como de las prohibiciones y repercusiones que la ocasiona la disposición inadecuada de residuos sólidos.

- Poco control por parte de las autoridades competentes: se requiere un control más continuo y riguroso de parte de las Autoridades Ambientales a los generadores de residuos sólidos, de cualquier sector productivo, a fin de diagnosticar situaciones y proponer alternativas de solución.

\subsection{Esquema de gestión}

El manejo de los residuos requiere de una visión integral, que implique no solo disponer los residuos generados, sino evitar su producción y reintroducir lo generado, como materias primas en la cadena productiva, evitando con esto que lleguen a los sitios de disposición final. Una verdadera gestión integral de residuos sólidos, debe involucrar los componentes de prevención, reciclaje, tratamiento y disposición final, así como los diferentes tipos de residuos: residenciales, comerciales, industriales, institucionales, hospitalarios y similares, peligrosos, escombros, lodos, barrido de áreas públicas, limpieza de parques y jardines y agrícolas. 
Para garantizar el cumplimiento de los ítems mencionados, se requiere el trabajo mancomunado de entes públicos y privados, que aúnen esfuerzos y recursos financieros necesarios para la ejecución de planes, programas y proyectos en materia de residuos sólidos. Uno de los entes públicos que viene trabajando desde años atrás, en lograr una adecuada gestión de los residuos sólidos, es el Área Metropolitana del Valle de Aburrá, quien formulo en el año 2005, con el apoyo de la Universidad de Antioquia, el Plan de Gestión Integral de Residuos Sólidos Regional. En éste se identificaron los principales problemas en materia de residuos y se formularon y priorizaron los proyectos para solucionar las problemáticas identificadas. A continuación, se exponen los proyectos que surgieron en el PGIRS-R.

Como complemento a las acciones emprendidas por los entes mencionados, se proponen algunas medidas, tendientes a minimizar los efectos de las problemáticas encontradas en las microcuencas estudiadas en la presente investigación. Las alternativas propuestas, incluyen los componentes técnico, normativo, y educativo, buscando entre ellos sinergias que redunden en soluciones costoefectivas y prácticas para la región.

\subsubsection{Componente técnico}

Desde el punto de vista técnico, se requiere con urgencia el desarrollo de proyectos relacionados con el recurso hídrico y en materia de residuos solidos que corrijan lo problemáticas estudiadas en la presente investigación, dentro de los cuales se encuentran:

\subsubsection{Canalización de cauces}

Debido a la torrencialidad de las quebradas de la región y a los altos caudales que se generan en épocas de invierno, se requiere con urgencia la canalización de ciertos tramos de las quebradas, primordialmente de aquellos en los cuales hay viviendas cercanas. La canalización permitirá encausar la dirección de la corriente, así como disipar la energía que trae; de la misma manera se disminuye el transporte de materiales hacia las partes mas bajas de las microcuencas que causan altas tasas de sedimentación y desbordamientos por la colmatación del canal.

También se contribuirá a que las obras de infraestructura por las cuales circula el agua, tengan una mayor estabilidad, debido a que cuando el cauce es natural, se presentan mayores tasas de socavación por el choque del agua con éstas. Las viviendas asentadas sobre márgenes no serán tan vulnerables a la ocurrencia de desbordamientos e inundaciones, ya que hay un control parcial en la velocidad y en los niveles de agua, que no pueden regularse cuando el canal es natural. 


\subsubsection{Construcción de estructuras hidráulicas para retención de sedimentos}

Para evitar el flujo de materiales hacia las zonas bajas, se requiere la construcción de estructuras hidráulicas que permitan la retención de sólidos, especialmente los de mayores tamaños que causan altos niveles de energía de la corriente y socavación de márgenes. Dentro de éstas se encuentran: azud, vertederos y diques, páneles o barreras físicas sumergidas

\subsubsection{Definir explotación adecuada de materiales en zonas de depositación de sedimentos.}

Se debe definir la manera más conveniente de explotar los materiales de playa en las zonas de depósito evitando cambiar las condiciones del cauce y el flujo de manera drástica. Para ello, se puede realizar el diseño de estructuras que permita la explotación de los materiales facilitando su obtención y se debe instruir a quienes realizan la labor de explotación sobre la metodología adecuada para causar un menor impacto en las condiciones naturales del cauce.

\subsubsection{Recuperación de cauce, extrayendo escombros y/o dragado.}

Para recuperar las condiciones hidráulicas del cauce, se requiere retirar todos los materiales de generan estrechamientos del canal, socavación y sedimentación. La extracción de arenas, gravas, y materiales de menor tamaño pueden realizarse a través de dragado, mientras que los materiales de mayor a través de maquinaria pesada.

\subsubsection{Reubicación de viviendas en alto riesgo}

Con el propósito de garantizar un mejor bienestar a las comunidades asentadas en las zona de influencia de las microcuencas, se requiere que los municipios promuevan y adquieran los recursos necesarios para la ejecución de programas de corte social, enfocados a la construcción de viviendas de interés social para reubicar a toda la población asentada en las riberas de las quebradas, que en épocas de invernales, se ven afectadas por catástrofes naturales, perdiendo parcial o totalmente sus enseres y viviendas.

\subsubsection{Limpieza de laderas y cauces}

Se requiere con mayor periodicidad la limpieza de canales y de márgenes de las microcuencas, en la cual se extraigan todos los residuos sólidos que generan taponamientos y problema de transporte del agua. Adicionalmente, las autoridades municipales a través de las Secretarías de Medio Ambiente deben inspeccionar con mayor frecuencia los sitios críticos en los cuales se 
presentan botaderos clandestinos de residuos ordinarios y de escombros evitando de esta forma mayores problemas ambientales y sanitarios a la comunidad.

\subsubsection{Aumento en coberturas de recolección}

Aunque las empresas de aseo reportan coberturas de recolección superiores al 95\%, algunas zonas urbanas de los municipios que conforman la región, cuentan con un servicio de aseo de regulares condiciones, con frecuencias y horarios inconstantes, que ocasionan traumatismos y la necesidad de evacuar de las viviendas los residuos sólidos que allí se generan. En las zonas rurales las coberturas bajan significativamente, encontrándose valores del orden del $50 \%$.

\subsubsection{Componente educativo}

Con la educación ambiental se pretende fomentar actitudes de cooperación; que la comunidad comprenda que actuar juntos es el pilar fundamental para dar respuesta y solución a los problemas ambientales. Una pieza clave, es promover el trabajo mancomunado, a través del uso de técnicas participativas, de tal forma de construir experiencias significativas que logren una mejor gestión de los residuos sólidos. Con un programa eficiente de educación ambiental se contribuirá a la socialización y realización de estrategias de uso, manejo y conservación de los recursos naturales, así como a la concientización de las poblaciones sobre los problemas del medio ambiente, la importancia de la conservación y las posibles formas de convivir en armonía con la naturaleza.

Con respecto al tema de residuos, la meta es avanzar hacia una sociedad sensibilizada, informada y educada hacia actitudes de "no desperdicio", de consumo con criterios selectivos. Que los gobiernos (nacional, regional y municipal), empresas, y ciudadanos tengan conciencia de sus actitudes y cambien las prácticas de disposición inadecuadas. Algunas de las acciones que pueden emprenderse en materia educativa son:

- Promover la reducción de la cantidad de los residuos sólidos que llegan a disposición final;

- Fomentar la responsabilidad compartida entre productores, distribuidores y consumidores en la reducción de la generación de los residuos sólidos y asumir el costo de su adecuado manejo.

- Promover sistemas de reutilización, depósito retorno u otros similares que reduzcan la generación de residuos, en el caso de productos o envases que después de ser utilizados generen residuos en alto volumen o que originen impactos ambientales significativos;

- Fomentar el desarrollo uso de tecnologías, métodos, prácticas y procesos de producción y comercialización que favorezcan la minimización y valorización de los residuos sólidos. 
- Crear e implementar la cátedra de residuos sólidos desde el nivel secundario hasta el nivel profesional, reconociendo la importancia del tema para el desarrollo de las actividades cotidianas de la sociedad actual

\subsubsection{Componente normativo}

Las normas en materia de residuos en el país han padecido desde sus inicios de problemas en su aplicabilidad y han sido objeto de diversas críticas, tanto del sector público como del privado.

Gran parte de las disposiciones dadas en éstas, son confusas, sobrerregulatorias e inviables para su aplicación práctica. Son muchos los factores que han llevado a que legislación no puede aplicarse en altos porcentajes, entre ellos, la cultura ambiental poco arraigada en la región y el escaso presupuesto de los entes de control, para la ejecución de proyectos en la materia.

Desde el marco normativo, la GIRS es entendida como el conjunto articulado e interrelacionado de acciones normativas, operativas, financieras, de planeación, administrativas, sociales, educativas, de monitoreo, supervisión y evaluación, para el manejo de residuos, desde su generación hasta la disposición final, a fin de lograr beneficios ambientales, la optimización económica de su manejo y su aceptación social, respondiendo a las necesidades y circunstancias de cada localidad o región. Armonizar las políticas de ordenamiento territorial y ecológico con el manejo integral de los residuos sólidos, identificando áreas apropiadas para la ubicación de infraestructura.

\subsubsection{Reformulación de normas en materia de escombros}

Debido a que la normatividad ambiental actual en el tema de escombros solo cuenta con la Resolución 541 de 1994, en la cual se reglamenta parcialmente el manejo de escombros en los componentes de recolección, almacenamiento y disposición final, se hace necesario la creación de nuevas normas que permitan tener un mayor control con los generadores, en cuanto a la presentación y disposición de los materiales mencionados. Las normas que se expidan en la materia deben mencionar de forma concreta y explicita la gestión integral de los escombros, la forma de presentación, recuperación y aprovechamiento. Este último componente es el que debe promocionarse con mayor fuerza debido a las grandes ventajas que ofrecen los escombros en los procesos constructivos. 


\subsubsection{Estimulo al aprovechamiento de residuos}

La región ha venido incrementando paulatinamente la separación en la fuente y el aprovechamiento de residuos sólidos de carácter reciclable en el sector residencial, desviando gran cantidad de materiales que tradicionalmente eran llevados a disposición final a las cadenas productivas para su transformación y comercialización. Aunque no se cuentan con rutas de selectivas, ni sistemas de recolección tecnificados con frecuencias y horarios definidos, el componente de recolección de material reciclable en los barrios es realizado a través de los recuperadores informales. De manera gradual, la comunidad ha venido tomando conciencia en las prácticas de manejo residuos sólidos, con altas tendencias al aumento de la separación en la fuente, pero sin estímulos tributarios dada la disminución en la disposición final y al incremento de beneficios económicos por comercialización de los mismos.

\subsubsection{Reglamentación para la explotación y extracción de materiales}

La extracción y explotación de materiales aguas arriba de las microcuencas, es un caso recurrente en la mayoría de los municipios de la región; ésta actividad se refleja en la calidad del agua, que se ve limitada por el aporte de sólidos y el transporte de materiales de diferentes tamaños que ocasionan colmatación y sedimentación del cauce.

Aunque esta actividad está reglamentada por las Autoridades Ambientales a través de las licencias y planes de manejo ambiental, exigidos para su normal operación, son evidentes los efectos que las escombreras y canteras ocasionan sobre el recurso hídrico, debido al irregular y desordenado manejo que se le da. El control ambiental y técnico realizado a dichos sitios, no es suficiente para garantizar el cumplimiento total de los planes de manejo ambiental y de la minimización de los impactos ambientales ocasionados por el desarrollo de sus actividades. Es necesario que las entidades gubernamentales reglamenten de una manera mas estricta el funcionamiento de los sitios en mención, adecuando estructuras hidráulicas que minimicen el transporte de materiales hacia sitios cercanos y su escurrimiento a microcuencas, además de la implementación de programas en materia ambiental que minimicen y compensen el impacto como la siembra de árboles, empradización de taludes, construcción de cunetas y sedimentadores, entre otros.

\section{Conclusiones}

Los análisis de agua a pesar de mostrar valores altos en cuanto a la presencia de materia orgánica e inorgánica, no son una prueba que confirmen que toda la intervención de las microcuencas es producto del vertimiento de residuos sólidos y escombros; además, la investigación por ser un ejercicio académico, contó con pocos recursos económicos, 
permitiendo realizar un muestreo puntual y no de manera continua en diferentes épocas del año. Dichas razones, dan pie a afirmar que la hipótesis propuesta en la investigación, no es comprobable a cabalidad para cada una de las microcuencas estudiadas, requiriendo de la realización de un monitoreo de calidad de agua mas exhaustivo para determinar a ciencia cierta el grado de afectación.

- De acuerdo con los recorridos de campo, la problemática recurrente a lo largo de quebrada La Hueso es la presencia de materiales de arrastre producto de la explotación a través de canteras, que incide especialmente en el aporte de sólidos en suspensión y en la turbiedad del recurso. En menor escala se encuentran los vertimientos de residuos sólidos y escombros, aportando bajos niveles de materia orgánica e inorgánica al agua, razón por la cual no puede comprobarse a cabalidad la hipótesis de la investigación.

- La prohibición de la explotación de materiales es una de las principales alternativas que plantearon los entes de control ambiental y gubernamental para mitigar los efectos sobre la cuenca, sin embargo, esta actividad genera empleo y recursos para la población, razones de peso valederos para autorizarla. Se ha pensado en la construcción de estructuras hidráulicas que retengan arenas y rocas desde sus sitios de origen y en parte alta de la quebrada, sin embargo, se requieren altas sumas de dinero para poder ejecutar todas las obras propuestas.

- La quebrada La Hueso genera grandes dificultades en las épocas de inviernos, pues es recurrente su desbordamiento en el sector Eduardo Santos (parte alta) y Suramericana (parte baja). Esta situación conlleva a sobrecostos en el servicio de mantenimiento y aseo para la administración municipal y las EPSA's, ya que requiere de personal experto para la adecuación de los canales afectados y de cuadrillas adicionales de aseo para recolectar y disponer adecuadamente los materiales y residuos que se generan por las altas crecientes. El río Medellín también se ve afectado por las condiciones sanitarias e hidráulicas que presenta La Hueso. Aunque muchos de los materiales de arrastre se extraen previamente antes de la desembocadura, algunos de ellos pasan al canal del río aumentando todos los parámetros estudiados, especialmente los sólidos y la turbiedad.

- En la quebrada La lguaná, a pesar de sólo tener un muestreo puntual, puede establecerse que el vertimiento de residuos sólidos y escombros si influye sobre la calidad del agua debido a las altas cargas orgánicas e inorgánicas que se encontraron a través de los análisis de laboratorio, comprobándose de esta forma la hipótesis de la investigación. Además, se presentan otras situaciones que disminuyen aun más la calidad del recurso, como son el vertimiento de aguas residuales domésticas e industriales, explotación y extracción de arenas en la parte alta, actividades ganaderas y porcícolas, utilización de agroquímicos para cultivos en la zona rural, entre otras.

- La problemática preponderante escogida inicialmente para la quebrada La García, si es el vertimiento de escombros, por lo tanto, la influencia de dicha práctica de disposición final es 
un factor determinante cuando se habla de afectaciones en la calidad del recurso. Además de ésta, otros factores que cobran importancia son la explotación de arenas y otros materiales en la zona alta, así como las características hidráulicas de la microcuenca que favorecen el desplazamiento de rocas y sedimentos a las zonas bajas, poniendo en riesgo a la población ribereña, que por lo general es de bajos recursos.

- Las problemáticas identificadas en cada una de las quebradas monitoreadas, son desfavorables para el río Medellín, ya que es un receptor directo de las aguas de éstas y las características fisicoquímicas que ellas traen, suman aún más el aporte de cargas contaminantes en cantidad y calidad. Aunque las condiciones hidráulicas del río Medellín son diferentes a las de las quebradas, en cuanto a pendientes, ancho y forma de canal, los fenómenos de transporte en éste se ven alterados por el aporte de gran cantidad de materiales flotantes como bolsas y recipientes plásticos, material vegetal, empaques de comestibles, así como de materiales inertes producto de los procesos constructivos y de explotación minera. Pese a que el río va degradando la materia orgánica y se va autorecuperando gradualmente a medida que continúa con su recorrido, es tanto el aporte que sufre de diversas fuentes receptoras, que su proceso de descontaminación no puede darse por si mismo, sino que requiere de soluciones técnicas que minimicen, mitiguen y corrijan los impactos ambientales y sanitarios producto de las actividades antrópicas.

La disposición inadecuada de residuos sólidos y escombros ocasiona impacto visuales y sanitarios negativos, además de los altos costos que deben asumir las autoridades gubernamentales y las empresas de aseo, que deben orientar nuevos recursos para limpiar y recoger los residuos y escombros dispuestos en sitos no adecuados, generando un doble gasto, que bien podría utilizarse para otras tareas de desarrollo comunitario. Las zonas rurales presentan menor intervención del paisaje, sin embargo, se desarrollan actividades que de una u otra forma repercuten sobre el recurso hídrico como son la explotación de materiales, ganadería, porcicultura, entre otras, que afectan el entorno de las zonas baja de la microcuenca.

- Aunque no pudieron determinarse los residuos flotantes como plásticos, trozos de madera, material vegetal, y otros transportados por la corriente, debido a las dificultades técnicas para su captura y caracterización, no puede desconocerse que éstos también inciden en la calidad de aguas.

- Una de las consecuencias más importantes ocasionadas por el vertimiento de escombros y residuos sólidos a laderas y cauces de las quebradas de la región, es la ocurrencia de los taponamientos del cauce, seguidos de desbordamientos e inundaciones. Estos fenómenos han casado graves dificultades de tipo social y económica para las comunidades cercanas a las quebradas, ya que sus viviendas y bienes materiales se deterioran parcial o totalmente, situación que conlleva a que los entes municipales y departamentales destinen nuevos dineros para la reubicación de viviendas y el otorgamiento de subsidios que les permita a las 
poblaciones afectadas, cubrir temporalmente sus necesidades y garantizar un mejor nivel de vida.

- Desde el punto de vista hidráulico, la presencia de escombros y materiales de arrastre en el cauce principal de las quebradas, son los causantes de la socavación y erosión de las márgenes de las quebradas. Los fenómenos de transporte de las corrientes, sumado a las altas crecientes generadas en épocas de lluvias, favorecen el deterioro de los canales y de todas las estructuras hidráulicas que regularan el caudal, los materiales de aluvión y sólidos, trasportados por la corriente.

- El vertimiento de aguas residuales fue una problemática recurrente en todas las microcuencas estudiadas, y podría considerarse como uno de los causantes en mayor proporción de la afectación del recurso, en especial en las quebradas La Hueso y La García. Este hecho, ocasiona una alta contaminación de la quebrada representada en la presencia de malos olores, contaminación visual, contaminación cruzada y en casos extremos, podría contribuir potenciando los efectos negativos durante la ocurrencia de crecientes e inundaciones. Además de esto, se presentan cambios físico-químicos en las características de las aguas de las quebradas, que afectan el régimen hidráulico, disminuyen la calidad biológica de la fuente de agua y generan la desaparición de especies vegetales y animales.

- Es evidente que las quebradas La Hueso, La García y La Iguaná presentan en sus márgenes residuos sólidos y escombros, sin embargo, no todos los que se vierten en éstas van a parar en el cauce principal. Un porcentaje de éstos, especialmente los de naturaleza orgánica, sufren descomposición por factores ambientales, en el sitio en el cual fueron vertidos; además, la limpieza realizada a las laderas por parte de las empresas de aseo y entes municipales, posterior al vertimiento de los mismos, es un factor que también favorece que éstos no se depositen directamente en el cauce.

- Las causas mas frecuentes que conducen a la ocurrencia de prácticas inadecuadas de disposición final se clasificaron en tres grandes grupos, relacionadas con componentes sociales, técnicos y legales. En la primera se encuentran los bajos niveles educativos y poco sentido de pertenencia frente al deterioro ambiental, dejando de lado el bienestar y calidad de vida que se reduce por condiciones sanitarias y ambientales adversas. El componente técnico hace referencia a las dificultades en la prestación servicio de aseo, cuya eficiencia y cobertura en algunas zonas no son suficientes para evitar que las poblaciones evacuen adecuadamente de sus viviendas, los residuos sólidos que generan. En último lugar se encuentra el componente legal, en el cual se evidencia el desconocimiento de gran parte de la comunidad frente a las normas y políticas existentes en el tema de estudio. También se cuenta con normas muy generales, abordando pocos niveles de detalle que permiten conocer cuales son las herramientas necesarias para garantizar un óptima gestión de los residuos. 
- El esquema de gestión propuesto en la investigación está enfocado a la formulación y ejecución de aspectos técnicos que tienen relación con la limpieza de cauces, retención de sólidos a través de estructuras hidráulicas y aumentos en las coberturas de recolección que permitan minimizar el impacto ambiental, sanitario e hidráulico ocasionado por la presencia de materia orgánica y materiales de arrastre en la corriente. Del mismo modo, se propone la ejecución de programas educativos enfocados a la prevención de la contaminación ambiental, dirigidos a toda la población de la zona de influencia de las microcuenca, evitando la ocurrencia de nuevas citaciones que pongan en riego su calidad de vida. Desde el punto de vista legal, se plantean programas como la creación de estímulos a los generadores para el aprovechamiento de residuos, que minimicen la disposición final y aumente la reincorporación de residuos en cadenas las productivas, sumado a la reformulación de normas que permitan controlar exhaustivamente la explotación de materiales y la disposición final de escombros. 


\section{Referencias Bibliográficas}

ÁREA METROPOLITANA DEL VALLE DE ABURRA. 2007 Plan de Ordenamiento y Manejo de la Cuenca Aburrá Pomca.

AMERICAN WATER WORKS ASSOCIATION. 2005 Standar Methods for the examination of water and waste water. 21 Edición.

ÁREA METROPOLITANA DEL VALLE DE ABURRÁ - UNIVERSIDAD DE ANTIOQUIA. 2005 Plan de Gestión Integral de residuos sólidos Regional PGIRS-R.

ÁREA METROPOLITANA DEL VALLE DE ABURRÁ-UNIVERSIDAD NACIONAL SEDE MEDELLÍN. 2006 Documento de soporte dirigida a generadores de residuos objeto de la Resolución Metropolitana 526/04.

FUNDACIÓN CODESARROLLO-EMPRESAS VARIAS DE MEDELLÍN. 2005 Plan de Gestión Integral de residuos sólidos de Medellín PGIRS.

INSTITUTO MI RÍO. 1997 Levantamiento Integrado de Cuencas hidrográficas en el Municipio de Medellín.

MUNICIPIO DE BELLO. 2008 Proceso de revisión y ajuste del plan de ordenamiento territorial del municipio de Bello.

ASTM INTERTATIONAL. Norma ASTM D42 1-58 y D-422-63.

UNIVERSIDAD DE ANTIOQUIA, UNIVERSIDAD DE MEDELLÍN, UNIVERSIDAD NACIONAL, UNIVERSIDAD PONTIFICIA BOLIVARIANA..2005 Diseño y puesta en marcha de la red de monitoreo ambiental en la cuenca hidrográfica del río Medellín, en jurisdicción del Área Metropolitana. Fase I. diciembre de.

'Guía Metodológica para la evaluación del impacto ambiental. Editorial Mundiprensa. 1997

${ }^{2}$ American Water Works Association. 21 Edición. 2005

${ }^{3}$ Constituye un indicador de la cantidad de materia orgánica biodegradable presente en el agua. La DBO5 se utiliza, igual que la DQO y la COT, como una medida de la capacidad contaminante de un vertido. Se determina midiendo el consumo de oxígeno, al cabo de cinco días, debido a la acción de los microorganismos en una muestra de agua conservada a $20^{\circ} \mathrm{C}$ de temperatura. Su concentración se expresa en miligramos de oxígeno/litro (mg O2/l) o partes por millón (ppm). En: http://platea.pntic.mec.es/ cmarti3/2000/sesion/eema/anexo.htm 
Impacto Ambental y Social del Vertimiento de Residuos Sólidos y Escombros Sobre la Calidad del Río Medellín y Algunos de sus Afluentes

${ }^{4}$ Indica de forma muy aproximada la cantidad de materia orgánica presente en el agua, aunque también existen sustancias inorgánicas oxidables que contribuyen a la DQO. Su concentración se suele expresar en miligramos de oxígeno/litro (mg $O 2 / \mathrm{I}$ ) o lo que es lo mismo partes por millón (ppm). La Demanda Química de Oxígeno es la cantidad de oxígeno consumida por la oxidación total de la materia orgánica presente en el agua, mediante un reactivo químico (normalmente permanganato o dicromato). En: http://platea.pntic.mec.es/ cmarti3/2000/sesion/eema/anexo.htm 